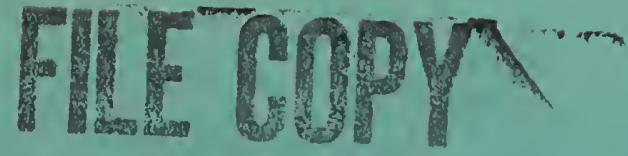

\title{
NISTIR 4566
}

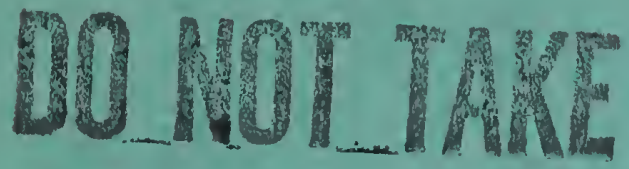

Properties and

Interactions of Oral Structures and Restorative Materials
J. A. Tesk

J. M. Antonucci

M. Y. M. Chiang

W. E. de Rijk

S. M. Kenny, III

J. E. MoKinney

J. W. Stansbury

K. Asaoka

G. W. Cheng

T. Matthews

K. Miyazaki

J. Tang

U.S. DEPARTMENT OF COMMERCE National Institute of Standards and Technology

Materials Science and Engineering Laboratory

Polymers Division

Dental and Medical Materials

Gaithersburg, MD 20899

Prepared for:

National Institute of Dental Research

Bethesda, MD 20892

U.S. DEPARTMENT OF COMLIIECE

Robert A. Mosbacher, Secretary

NATONAL INSTIUUE OF STANDATDS

AND TECHNOLOGY

Jotm W. Lyons, Director

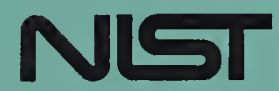



Properties and Interactions of Oral Structures and Restorative Materials

\author{
J. A. Tesk \\ J. M. Antonucci \\ M. Y. M. Chiang \\ W. E. de Rijk \\ S. M. Kenny, III \\ J. E. McKinney \\ J. W. Stansbury \\ K. Asaoka \\ G. W. Cheng \\ T. Matthews \\ K. Miyazaki \\ J. Tang
}

U.S. DEPARTMENT OF COMMERCE National Institute of Standards and Technology

Materials Science and Engineering Laboratory

Polymers Division

Dental and Medical Materials

Gaithorsburg, MD 20899

Prepared for:

National Institute of Dental Research

Bethesda, MD 20892

Annual Report for Period

October 1, 1989 to September 30, 1990 Issued May, 1991

Interagency Agreement

Y01-DE30001

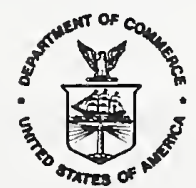

US. DEPARTIMENT OF COMMERCE

Robert A Mosbacher, Secretary

NATONAL INSTIUUIE OF STANDARDS

AND TECHNOLOGY

John W. Lyons, Director 

ABSTRACT . . . . . . . . . . . . . . . . . . . . v

STAFF. . . . . . . . . . . . . . . . . . . . . . vi

SIGNIFICANT ACCOMPLISHMENTS. . . . . . . . . . . . . . . . . . . vii

INTRODUCTION . . . . . . . . . . . . . . . . . . . viii

PART I - COMPOSITES, CEMENTS, AND ADHESION (Antonucci, Stansbury, Miyazaki, and Cheng)

\section{Section A through E - Antonucci, Stansbury}

A. Improvement of Dental Composites, Sealant Cement

and Adhesive Materials. . . . . . . . . . . . . . .1

I. Improvement of Dental Resin Systems for Composites and Sealants... . . . . . . . . . . . .2

A.1 Monomers which Polymerize with Expansion. . . . .2

A. 2 Lactone Monomers. . . . . . . . . . . . . 7

A. 3 Low Surface Energy Resin Based Composites and Synthesis of New Types of Fluoro and

Siloxane Resins. . . . . . . . . . . . . . 9

A.4 Cyclopolymerizable Monomers. . . . . . . . . 10

A. 5 Synthesis of Organometallic and Related

Monomers. . . . . . . . . . . . . .15

A. 6 Effect of Post Cure Storage Time on the

Properties of Composites. . . . . . . . . .16

A.7 Initiator Systems. . . . . . . . . . . 17

B. Improvement of Filler Systems for Composites and Cements................. . 18

C. Improvement of Interfacial Bonding Systems. . . . . . 19

D. New Resin Systems and Pretreatment Techniques

for Bonding to Dentin. . . . . . . . . . . . . 20

E. Improvement of Dental Cements. . . . . . . . . . . 22

References . . . . . . . . . . . . . . 25 
PART II - WEAR RESISTANCE AND DURABILITY ASSESSMENT OF

OF DENTAL COMPOSITE RESTORATIVE MATERIALS

(McKinney, Antonucci, de Rijk, Keeny)

A. Wear and Durability Assessments of Composite

Restoratives. . . . . . . . . . . . . . 34

B. Assessment of Wear of Human Enamel Against

Restorative Counterfaces. . . . . . . . . . . .38

C. Wear Instrumentation. . . . . . . . . . . 39

References . . . . . . . . . . . . . . . . 42

PART III - DENTAL ALLOYS, CERAMICS, AND METROLOGY

(Tesk, Chiang, de Rijk, Keeny and Asaoka)

A. Porcelain-Alloy Compatibility (Thermo-

Mechanical Stress) . . . . . . . . . . . . . . 44

B. Porcelain-Alloy Compatibility: Strength of Porcelain-

Metal Systems. . . . . . . . . . . . . . 49

C. Castability (Filling of a Mold with Cast

Dental Alloy). . . . . . . . . . . . . . . 49

D. Castability (Accuracy of Fit of Dental Castings) . . 50

E. Solderability. . . . . . . . . . . . . . . 50

F. Metrology and Analysis: Measurements for

Characterization of Dental Materials. . . . . . . . .50

G. Metrology and Analysis: Occlusal Force Indicator. . . 50

H. Metrology and Clinical Performance. . . . . . . . 51

I. Metrology and Analysis: Stress in Dental Composites

Bonded to Teeth. . . . . . . . . . . . . . . 53

J. Metrology: Sterilization of Dental Instruments. . . .54

References. . . . . . . . . . . . . . . 56

Publications. . . . . . . . . . . . . . . . 58

Manuscripts Under Review or Accepted for Publication. . . . 59

Conferences/Special Meetings. . . . . . . . . . . . 59

Contributed Talks. . . . . . . . . . . . . . . . 59

Invited Talks. . . . . . . . . . . . . . . 60 
The research program described herein is designed to achieve a number of objectives leading to improved dental restorative materials, techniques, and applications of dental materials science for improved dental health care in general. Some of the research in dental composites is directed toward developing generic polymer science potentially useful for composite applications, e.g., durable resin matrices and stronger more durable coupling between fillers and resins. Improved reinforcement is sought by defining the type, and percentages of fillers which will result in improved performance of composites. Methods for reducing polymerization shrinkage and attendant stress and marginal leakage are also explored. Cements are investigated and basic formulations developed for lower solubility, higher biocompatibility, higher strength, greater toughness and adhesion to various substrates including enamel and dentin. Analysis techniques include IR spectroscopy, chromatography, $x$-ray analysis, mechanical testing, and dilatometry. Another major effort is directed at elucidating the fundamentals involved in wear and degradation of dental composites and restoratives. Wear and hardness measurement techniques are used as well as identification of the origins and sources of flaws leading to failure. Weibull statistical analysis is expected to provide useful information for this task. In this regard an objective is to investigate improved correlations between clinical results of wear and failure with laboratory test data. Metrology and analysis constitute the underlying theme of investigations into porcelain-metal systems, casting of dental alloys and the expansion of dental casting investments.

"The activity covered by this agreement consists of work which requires the definition of measurement methods, materials property data, and standards of basic scientific and engineering units and the application of primary standards to insure equity and comparability in U.S. commerce, international trade, and technical activities. As such it complies with OMB Circular A76, revised under paragraph $5 f$ (Activities classified as Government responsibilities or are intimately related to the public interest)." 
DENTAL AND MEDICAL MATERIALS GROUP

J.A. Tesk, Group Leader

NIST Personnel

J.M. Antonucci

M.Y. Chiang

S.F. Harlow

S.M. Keeny, III

\section{s. Ctr.}

R.L. Bowen, Director

W.E. Brown, Dir. Em.

P.S. Bennett

C.M. Carey

M.W. Chalkley

A. Chohayeb

L.C. Chow

M.L. Conner

F.C. Eichmiller

N. Eidelman

M. Farahani

A.A. Giuseppetti

T.M. Gregory

A.D. Johnston

N. Lopatin

A. Ly

W.A. Marjenhoff

M. Mathew

D.N. Misra

N.W. Rupp

B. Sieck

S. Takagi

B.B. Tomazic

M.S. Tung

S. Venz

G.L. Vogel

R.M. Waterstrat

\section{NIDR}

E.D. Eanes

B.0. Fowler

A.W. Hailer
Industry

C.A. Goodman

Air Techniques

\section{Guest Scientists}

M. Anderson, U.S. Navy

G. Buchness, Univ. of Maryland

G. Cheng, West China Univ. of Med. Sci.

$\mathrm{J}$. Hoffman, Catholic Univ. of Am.

K. Kallander, U.S. Navy

T. Matthews, Howard Univ.

J. McKinney, Retired NIST

J. Meyer, NIDR
K. Miyazaki, Fukuoka Dent. Coll.

G. Schumacher, NIDR

D. Skrtic, NIDR

H. Strassler, Univ. of Maryland

R. Taft, U.S. Navy

J. Tang, Shanghai Pharm. Inst.

V. Thompson, Univ. of Maryland

M. Waterman, U.S. Navy 
- New spirocyclic monomers were developed which take advantage of the reactivity of a conjugated diene functionality to accomplish the desired ring-opening polymerization with expansion. The monomers homopolymerize well at ambient temperature in contrast to prior spiro orthocarbonates which were much more sluggish toward free radical addition. The bulk homopolymers offer high modulus compared to other ring-opened polymers due to crosslinking.

- Oxybismethacrylate monomers composed of an ether-fused 1,6-diene linkage and pendant ester functionality were further evaluated. These monomers offer significantly lower degrees of polymerization shrinkage compared with conventional dimethacrylates. The use of bulky ester groups was found to maximize the intramolecular cyclization mode of polymerization that is responsible for the decreased shrinkage.

- Novel, highly fluorinated difunctional and multifunctional vinyl monomers were prepared based on a modification of the method used for the syntheses of analogous hydrocarbon cyclopolymerizable monomers.

- Vinyl metal carboxylate monomers based on mono-[2-(methacryloyl)oxy ethyl)phthalate were synthesized and shown to have a number of potential dental applications, e.g. as radiopacifying resins.

- Research into the microbicidal effects of microwave generated gas plasmas was completed. Kill kinetics of Bacillus subtilis spores indicated that gas plasmas can kill six log load of spores on representative substrates surfaces with an energy input of 60 kJoules (i.e. 600 watts for 100 seconds). However, low end probability of sterility studies using stainless steel cylinders showed that end point sterilization of objects required 2 to 3 times this energy input. At the longer exposure times for complete sterilization, substrate temperatures approached 170 degrees, and the air plasma appeared to damage the surface of stainless steel objects.

- A new wear machine is near completion and design problems have been identified and corrected. The old wear machine was interfaced with a new PC computer controller.

- A viscoelastic model of stress in a porcelain-metal system showed that curvature of a slab or a split ring is not a sensitive indication of residual stress.

- Experimentation on the internal setting expansion of phosphate-bonded dental investment showed effective internal setting strain differences of only 0.158 between directions parallel to a casting-ring axis and perpendicular to the axis.

- A combined Weibull risk-of-rupture analysis and finite element stress analysis was shown capable of delineating the origin of failure for specimens of dental casting alloys bonded by adhesive resin; this points to the usefulness of such a combined experimental and analytical approach to identifying the weakest links of bonded systems. 


\section{INTRODUCTION}

The following pages contain reports on work involved with the development of basic generic science and engineering that is expected to be useful in the development or control of dental materials used for restorative or treatment purposes. Some of the developments involve investigations of new dental resin formulations (Part I) which might improve the performance of dental composites. Cements and adhesion to filler particles or tooth structure are also addressed in this part.

Part II deals with examination of the basic parameters affecting the wear and durability of materials with particular emphasis on dental composites. The resultant information is used to help guide developments in Part I.

Part III is concerned with dental casting alloys, and the strength of veneered dental systems (in particular, porcelain fused-to-metal) metrology, diagnostics and related topics. Factors affecting the castability of alloys and how to measure and define aspects of castability are addressed. Mathematical methods are employed to reveal effects of individual elements as well as other parameters such as investment variations. The strength of veneered systems is the characteristic receiving the most attention for the porcelain-fused-to-metal studies. Special emphasis is being placed on measurement techniques and flaw analysis. Weibull statistics is employed for analyses of the strengths of dental systems, time to failure etc. A special effort has also been mounted to explore the use of plasma's for sterilization of dental instruments. (Measurements of spore populations etc. will be conducted with the cooperation of the U.S. Navy). 


\section{A. Improvement of Dental Composites, Sealant Cement and Adhesive Materials}

\section{Overview}

The quest for a durable, esthetic, adhesive and biocompatible material suitable for the restoration of lost tooth structure has long challenged dental materials researchers. A significant step toward the realization of this goal was the development of resin-based dental composites which overcame many of the shortcomings of the silicate cements (purely inorganic composites) and unfilled resin restoratives (purely organic composites based on methyl methacrylate and its polymers). The synthesis of BIS-GMA by Bowen, ushered in the modern era of resin-based dental composite restorative materials and also other resin-based dental materials [1,2]. The essential components of dental composites are: (1) a resin system comprising one or more vinyl monomers which on polymerization forms the matrix or continuous phase, (2) reinforcing fillers such as radiopaque glasses, quartz, minerals, ceramics, organic and hybrid organic-inorganic powders of various: sizes; size distributions, and shapes comprising the dispersed phase, ( 3 ) an interfacial phase for bonding the continuous and dispersed phases, derived from vinyl silanes, titanates, i.e., coupling agents, (4) a polymerization initiator system effective under ambient conditions, and (5) stabilizers for optimizing storage stability and also preserving the chemical stability of the hardened restoration. Unlike glass ionomer cements that bond to tooth structure, current resin-based composites are non-adhesive in nature and still have a number of other problems that limit their wider application [1$54]$.

However, the acid-etch technique (Buonocore), in most situations, provides an effective micromechanical mechanism for bonding dental composites to enamel [49]. Bonding to dentin is a more challenging problem but recent developments appear to be yielding effective coupling agents for this substrate as well [55-63]. Efforts to enhance the durability and range of applications (e.g., posterior as well as anterior fillings) of dental composites include: optimization of the types, sizes, shapes and volume of the dispersed phase; reductions in the solubility parameter, residual vinyl unsaturation, and polymerization shrinkage of the resin phase and; the development of more effective interfacial bonding phases $[47,48,50-54,64$ 85 ].

Dental sealants have similar compositions and chemistry but are unfilled or only lightly filled and usually contain a higher proportion of diluent monomer(s). Similar resin-based materials also are widely used in other applications (e.g., adhesives, core build-up and crown and bridge materials, laminating veneers, etc.).

Dental cements, which also have a composite nature, find use in a wide variety of dental applications. In restorative dentistry they are employed as temporary, intermediate, and (in the case of glass ionomer cements) permanent filling materials. Their chemistry of hardening involves a series of acid-base reactions involving ion-exchanges that result in the development of a matrix into which are imbedded partially reacted basic filler particles [86-88]. An ion-exchange mechanism involving 
polyelectrolyte cements (e.g., glass ionomer) and mineralized tissue also may explain their adhesion to tooth structure [86-91].

Two types of dental cements can be distinguished depending on their water content: (1) those that are aqueous based (e.g., zinc phosphate, polycarboxylate, glass ionomer) in which water plays a role both in their setting and in the development of their molecular and micro structures, and (2) those that are relatively non-aqueous in nature, although catalytic amounts of water or other polar compounds (e.g., acetic acid) are needed to activate the acid-base reactions and to achieve clinically acceptable setting times for (e.g., ZOE, EBA, HV-EBA, dimer acid, etc.)

Basically this section is divided into four areas of research:

Improvement of Dental Resin Systems for Composites and Sealants. (Synthesis, Formulation and Evaluation)

Development of Improved Interfacial Bonding Systems and Fillers for

Composites and Cements.

(Synthesis, Formulation and Evaluation)

Bonding of New Resin Systems to Tooth Structure.

(Synthesis, Formulation and Evaluation)

Improvement of Dental Cements.

(Synthesis, Formulation and Evaluation)

I. Improvement of Dental Resin Systems for Composites and Sealants

Objective

The goal of this research task is to enhance the durability of dental composite, sealant, cement and adhesive materials through the use of lowshrinking, but highly thermosetting and stable resins.

\section{A.1 Monomers which Polymerize with Expansion}

\section{Background}

Polymerization shrinkage has been identified as a major deficiency inherent in all resin based dental materials[26-28,38,47,48,52-54]. The stresses resulting from contraction of the organic phase of composites can promote microcracking, debonding of the filler-polymer interface and marginal gap formation at the vulnerable composite-tooth interface. Efforts to minimize or eliminate polymerization shrinkage include: (1) the use of hydrophilic monomers to promote compensatory hygroscopic expansion[26-29] (2) maximization of filler content[52-54], (3) the use of oligomers and macromers [47,48] and (4) the use of monomers and oligomers that expand on polymerization [30-32]. A major emphasis is given to (4) as a strategy for reducing polymerization shrinkage. The major goal of this research is to synthesize reactive spiro monomers that undergo efficient ring-opening polymerization. 


\section{Accomplishments}

This research program, designed to provide monomers that polymerize with either no change in volume or a volume expansion, has been focussed on the free radical double ring-opening polymerization of spiro orthocarbonate monomers. These compounds are capable of $3-58$ volume expansion and can be used in conjunction with conventional dimethacrylate monomers to minimize or eliminate polymerization shrinkage. Our previous work in this area has demonstrated that liquid or low melting spiro monomers can be prepared by a synthetic procedure which yields asymmetric ring systems[32]. The series of free radical polymerizable spiro monomers shown below was synthesized and their copolymerization with styrene was evaluated. An analysis of the<smiles>C=C1COC2(OCC(C)(C)CO2)O1</smiles>

1<smiles>C=C1COC2(OC1)OCC(C)(C)CO2</smiles>

2<smiles>C=C1CCOC2(OC1)OCC(C)(C)CO2</smiles>

3

resulting copolymers demonstrated the enhanced reactivity of 1 compared with that of 2 or 3 . From these results and their homopolymerizations, monomers based on the 5-membered, exocyclic methylene-substituted dioxolane ring appear to offer the most promise in dental resin applications. Of the spiro orthocarbonates prepared to date, these monomers were found not only to be most reactive toward free radical addition, but were also the most efficient at achieving the desired double ring-opening during polymerization.

The effect on diametral tensile strength (DTS) of incorporating 46 mole percent of similar spiro monomers (with varying ring size) as diluent comonomers in BIS-GMA and EBPADMA-based composite formulations was evaluated. The resins were prepared as chemically initiated liquid/powder systems with $\mathrm{N}, \mathrm{N}$-di-(2-hydroxyethyl)-p-toluidine (DHEPT) in the liquid and benzoyl peroxide on the glass filler. For comparison, chemically activated control formulations of BIS-GMA/TEGDMA and EBPADMA/HMDMA were also included. The results, shown in Table 1 , demonstrate that the acceptable mechanical strength properties with BIS-GMA or EBPADMA based composites can be maintained even though the diluent is eliminated or reduced. This is somewhat surprising since these spiro monomers are inefficient at or incapable of crosslinking during free radical polymerizations. This would seem to suggest that they contribute to the network formatio by copolymerization. 
Table 1

DTS of Chemical Cured Composites

\begin{tabular}{lcc} 
Formulation & Wt. 8 & DTS, MPa \\
\hline BIS -GMA/TEGDMA & $70: 30$ & $52.6 \pm 1.8$ \\
BIS-GMA/1 & $76: 24$ & $48.6 \pm 2.5$ \\
BIS-GMA/2 & $72: 28$ & $46.7 \pm 1.2$ \\
EBPADMA/HMDMA & $90: 10$ & $42.1 \pm 1.5$ \\
EBPADMA/1/HMDMA & $68: 25: 7$ & $41.0 \pm 2.4$ \\
& \\
TEGDMA = Triethylene glycol dimethacrylate & \\
EBPADMA = Ethoxylated bisphenol A dimethacrylate & Esschem Co. \\
HMDMA = Hexamethylene 1,6-dimethacrylate &
\end{tabular}

\section{Monomer Synthesis}

Recent work has been directed toward the preparation of spiro monomers which demonstrate improvements in the following areas: 1) reactivity - so the spiro monomer can be effectively incorporated into a copolymer with conventional methacrylate monomers, 2) ring-opening efficiency - so the maximum degree of polymerization expansion can be achieved, and 3 ) modulus of the ring-opened polymer - accomplished through the introduction of backbone-stiffening substituents or by a crosslinking process.

A new spiro orthocarbonate which may satisfy all these criteria would be the benzo-fused monomer of the type shown for 4. This sort of monomer, with its "styrene-like" vinylidine group should have excellent reactivity and may favor ring opening due to steric crowding of the benzylic radical generated initially upon addition. Further, the ortho-phenylene unit in the backbone would serve to increase the glass transition temperature of the ring-opened polymer 5. Ring size and/or substituents on the second ring could be varied to manipulate properties such as melting point or ring-opening efficiency.

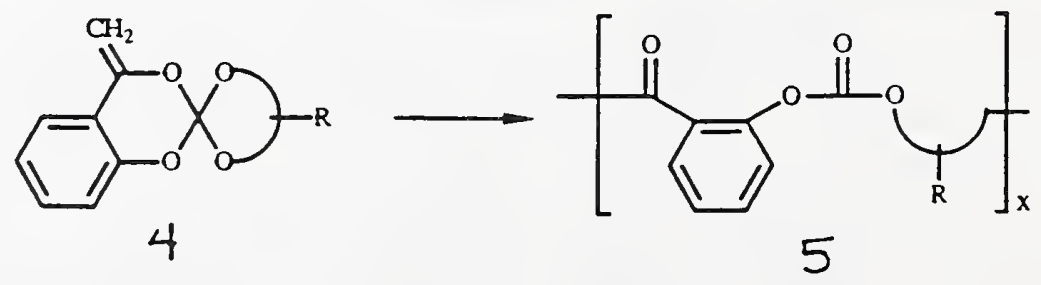

Prior efforts to synthesize monomer 4 through a five-step procedure were unsuccessful due to complications encountered for several of the intermediates. However, a new two-step pathway to this monomer has been devised as follows: 

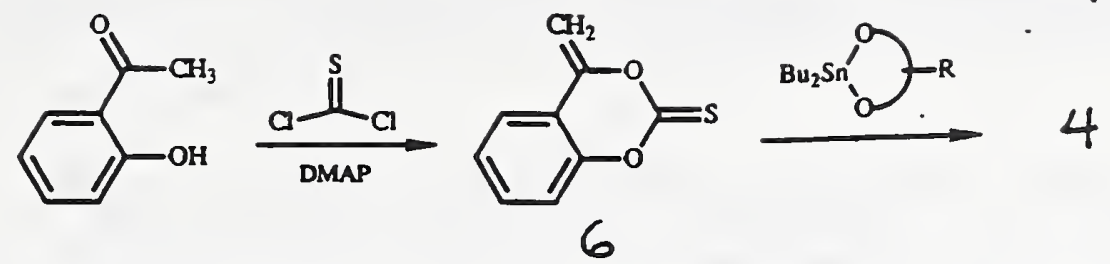

The cyclic thionocarbonate 6 , with the exocyclic double bond in place, has been prepared directly poor yield. Alternatively, the hydroxyacetophenone dimer with thiophosgene 7 can be easily synthesized in excellent yield. Upon treatment with base, the dimer undergoes quantitative cyclization to the desired thionocarbonate 6 with elimination of the hydroxyacetophenone starting material. The final step to provide the spiro monomer 4 has yet to be attempted but this reaction (independent of the exocyclic methylene group) is known to proceed in good yield at room temperature.

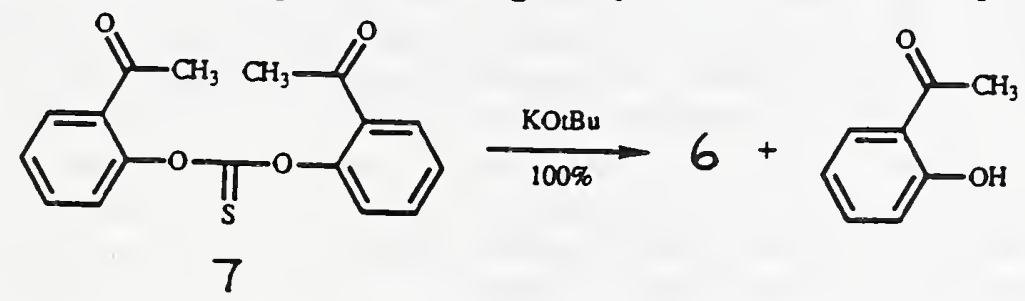

In a different approach, spiro orthocarbonates containing a 1,3-diene unit have been synthesized. These 2,3-bis(methylene) spiro monomers exhibit reactivities comparable to 1,3-butadiene and offer a means of achieving ring-opening polymerization with crosslinking. The synthesis of spiroorthocarbonate 8 involves the use of the recently commercialized 1,4dibromo-2,3-butanediol. This diol can be incorporated into the general synthetic procedure previously used to prepare the spiro monomers without any alterations in the method. Other monomers based on this same chemistry were also prepared. A phenyl-substituted analog 9 was designed to enhance ring opening while the triene monomer 10 will provide additional crosslinking.<smiles>OC(CBr)C(O)CBr</smiles><smiles>CC1(C)COC(=S)OC1</smiles><smiles>CC1(C)COC2(OCC(CBr)C(CBr)O2)OC1CBr</smiles><smiles>C=CC</smiles><smiles>C=C1OC2(OCC(C)(C)CO2)OC1=C</smiles>

8<smiles>C=C1OC2(OCC(c3ccccc3)O2)OC1=C</smiles><smiles>C=C1COC2(O1)OC(=C)C(=C)O2</smiles>

9

10

The synthesis of monomer 11 was carried out in order to ascertain the effect of a radical stabilizing phenyl substituent on the ring-opening process. 
The polymerization of this monomer can be compared with that of monomer 1 which was synthesized previously.

\section{Polymerization}<smiles>C=C1COC2(OCC(c3ccccc3)O2)O1</smiles>

11<smiles>C=C1COC2(OCC(C)(C)CO2)O1</smiles>

The homopolymerization of monomer 1 was examined in greater detail since dental composite formulations based on this ring-opening monomer have provided the best results to date. The studies demonstrated that the polymerization mechanism involved several pathways and was influenced by polymerization conditions, such as monomer concentration and temperature. The various pathways include: 1) 1,2-addition polymerization without ring opening (no bonds broken for each new bond formed), 2) double ring opening (two bonds broken per bond formed), and 3) single ring opening with elimination of a cyclic carbonate molecule (two bonds broken per bond formed). Therefore, while the 1,2-addition pathway represents a negative volume process, the latter two ring-opening modes offer expansion. The elimination pathway is not desirable, however, since this incorporates a nonbonded, leachable component into the polymer matrix.
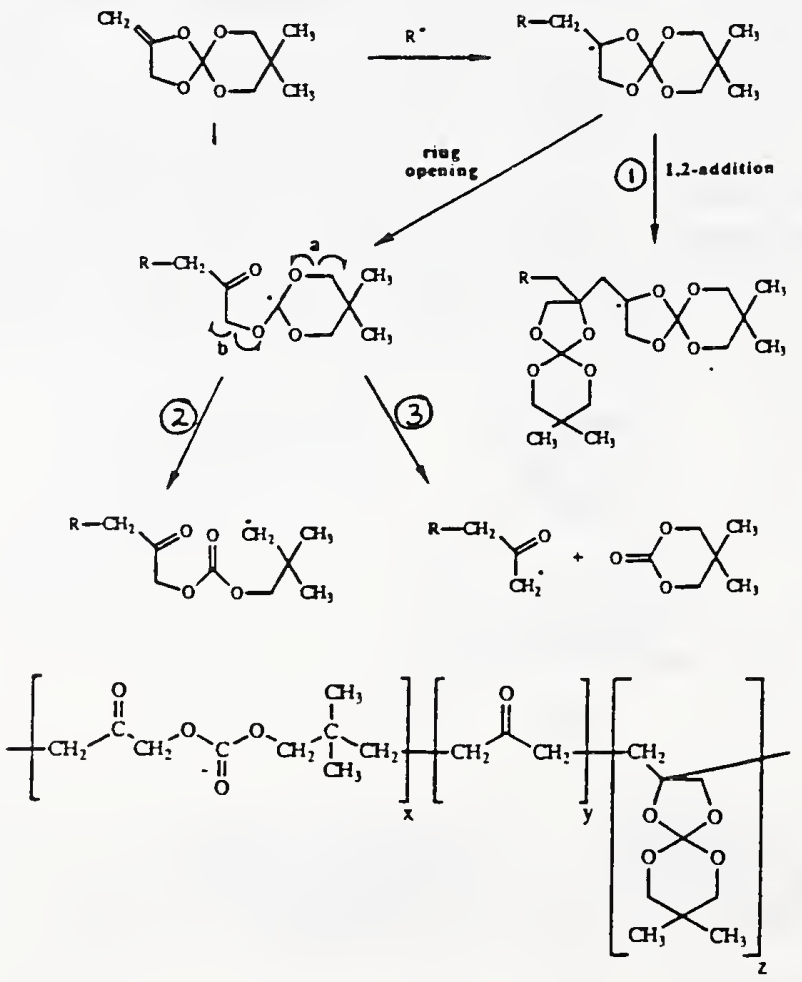

Preliminary studies with monomer 11 appear to indicate that the introduction of the radical-stabilizing phenyl substituent does not significantly 
increase the proportion of monomer undergoing polymerization with ring opening. However, it was beneficial in that the resulting polymer displayed more double ring opening and less ring opening with elimination than in the polymerization of monomer 1 .

The high yields of polymer obtained from the $65^{\circ} \mathrm{C}$ AIBN homopolymerizations of monomer 8 offer a demonstration of the greater reactivity associated with the 2,3-bis (methylene) group compared with the single exocyclic double bond in monomer 1. Bulk polymerization of 8 gave crosslinked polymer while the dilute solution polymerization in benzene provided a small soluble polymer fraction along with the crosslinked component. Analysis of the soluble polymer fraction shows no 1,2-addition and only a small amount of single ring opening with elimination while the main route appears to be the desired double ring opening. There is also evidence of the 1,4-addition pathway since some intact spiro groups are present in the polymer. There is also the potential for a complex addition/cyclization mechanism to be involved in the polymerization of these types of monomers. The volume change associated with the polymerization of the spiro monomers 8-10 based on the conjugated diene system will be determined in the near future.

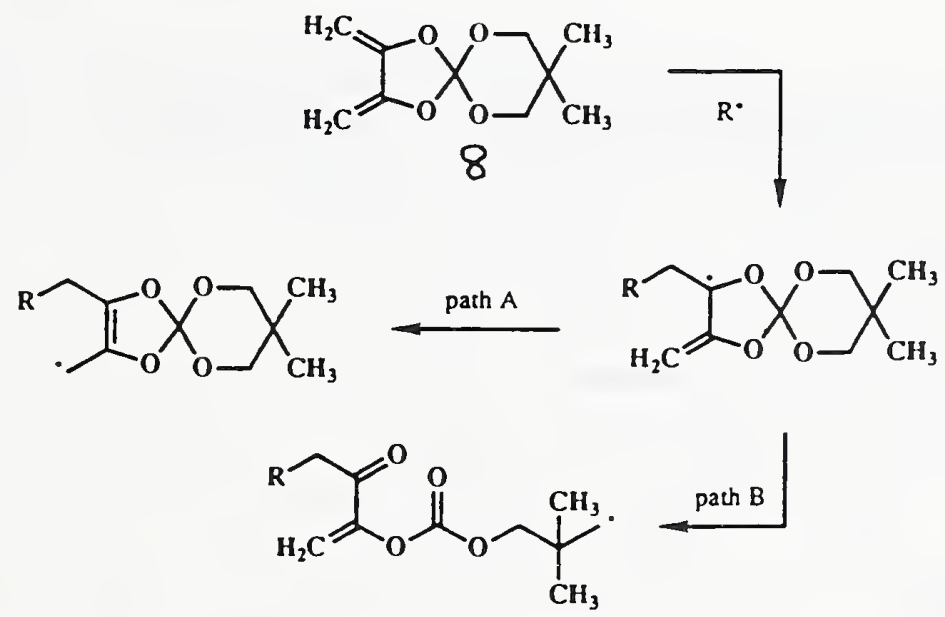

Formulation

No work on formulation or evaluation of these spiro monomers in dental resin compositions was conducted during this reporting period. However, a comparison of the effects of monomers 8 and 1 in dental composite formulations is now underway and will be reported on at the 1991 International Association for Dental Research (IADR) meeting.

\section{A. 2 Lactone Monomers}

\section{Background}

Our initial interest in $\alpha$-methylene- $\gamma$-butyrolactone compounds was to exploit the greater reactivity of these cyclic monomers compared with methacrylate monomers[64-69]. We postulated that the small, highly reactive $\alpha$-methylene$\gamma$-butyrolactone (MBL) monomer might improve the relatively low degree of conversion attained by dental composite materials. The significant amounts of residual unsaturation present in cured composites limit the mechanical strength properties, solvent resistance, durability and color stability of 
these materials[39-46,70-72]. Other advantages associated with $\alpha$-methylene lactones include their excellent solvent properties for other the monomers and the chemical resistance and high $\mathrm{T}_{\mathrm{B}}$ of their corresponding polymers.

Accomplishments

The lactone monomers already prepared (see Table 3) have been homopolymerized to provide linear (noncrosslinked) polymers which, depending on the substituents, exhibit a wide range of solvent resistance as shown in Table 3. These monomers will be incorporated into composite materials and subjected to wear testing in an effort to correlate wear rate and solvent resistance. Surface hardness measurements before and after storage in various solvents also will be performed. (See Part II)

Table 3

Lactone Polymer Solubility* in Chloroform and Dimethylformamide

Solvent

Monomer

$\mathrm{CHCl}_{3}{ }_{3}\left(23^{\circ} \mathrm{C}\right)$

$\operatorname{DMF}\left(50^{\circ} \mathrm{C}\right)$

$\operatorname{DMF}\left(>100^{\circ} \mathrm{C}\right)$<smiles>C=C1CCOC1=O</smiles>

insol.

insol.

sol.<smiles>C=C1CC2(CCCCC2)OC1=O</smiles>

sol.

sol.

sol.<smiles>C=C1CC(c2ccccc2)OC1=O</smiles>

insol.

sol.

sol.<smiles>C=C1OC(=O)c2ccccc21</smiles>

insol.

insol.

insol. 


\section{A. 3 Low Surface Energy Resin Based Composites and Synthesis of New Types of Fluoro and Siloxane Resins}

\section{PROGRESS REPORT}

\section{Background}

Fluorocarbon polymers, e.g. teflon, viton elastomers, etc., are noted for their extreme hydrophobicity and their ability to withstand harsh chemical environments. Polysiloxanes (i.e. silicone polymers) also have a high degree of hydrophobicity and exhibit excellent resistance to many aqueous based environments. Because of their low cohesive energy density, these polymers tend to be relatively weak materials unless they are highly crystalline, have rigid structural units or are highly crosslinked. The objective of this project is to prepare low surface energy monomers and oligomers that yield strong, tough polymers and composites on polymerization.

\section{Accomplishments}

Several composite formulations based on the highly fluorinated urethane methacrylate oligomer, PFUMA, derived from the polyfluoropolyol, PFP, were prepared [47]. In general, compared to composites based on PFMA, the highly fluorinated methacrylate oligomer, those based on PFUMA were stronger than those based on PFMA and almost as hydrophobic [48], PFUMA resins were found to be more amenable to visible light initiated polymerization than those based on PFMA, presumably because of the lower cohesive energy density and greater oxygen solubility of the PFMA monomer systems [70]. Compared to a similarly glass filled BIS-GMA resin, PFUMA composites demonstrated somewhat higher degrees of conversion and lower polymerization shrinkage [47]. Dual cured (photochemical and chemical initiation) PFUMA and PFMA based composite demonstrated better mechanical properties than similar chemical or photochemical cured composites [70]. The PFUMA and PFMA composites had excellent environmental resistance to simulated intraoral fluids but exhibited lower wear resistance than conventional composites [72]. The various polyfluoro oligomers, including the polyfluoroacrylate, PFA, are shown below.

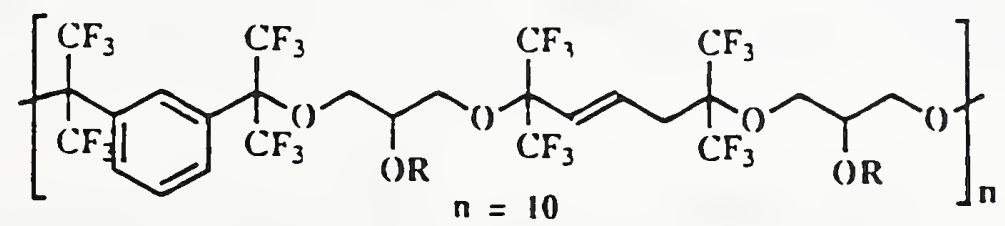

where $\mathrm{R}=$

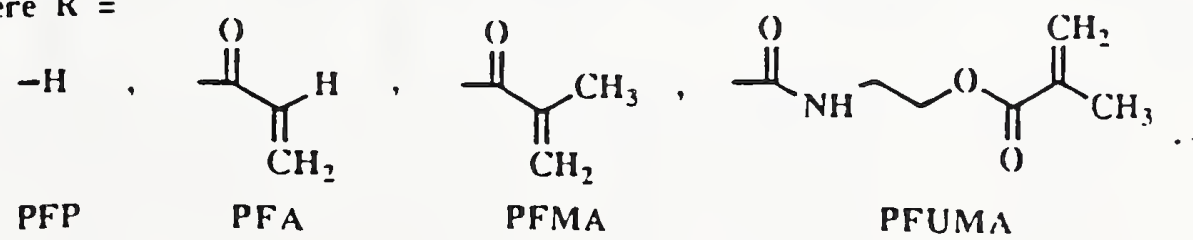


A new synthesis of highly fluorinated difunctional monomers and oligomers was developed based on the base catalyzed reaction of formaldehyde with fluoro acrylate monomers [50d]. This new, relatively facile synthesis provides a route to a number of new difunctional and multifunctional fluoro and siloxane resins, which, depending on their structure, can undergo cyclopolymerization and/or network polymerization (see A.4).

A.4 Cyclopolymerizable Monomers

PROGRESS REPORT

Background

The goal of this section of Part I of the proposal is to synthesize difunctional monomers and multifunctional oligomers capable of efficient cyclopolymerization. Cyclopolymerization has several desirable characteristics: 1) high degree of conversion of vinyl groups, 2) reduced polymerization shrinkage compared to analogous noncyclicizing monomers and (3) yields polymers with in chain cyclic structures which can raise the glass transition temperature $\left(T_{8}\right)$ and enhance their oral environmental resistance (OER). The efficient cyclopolymerization of suitable nonconjugated difunctional monomers has been a topic largely of academic interest in polymer chemistry since the discovery of this phenomenon by Butler and Marvel more than 30 years ago $[73,74]$.

\section{Accomplishments}

Our recent involvement with a new class of 1,6-diene monomers was based on the practical concern of achieving high conversion polymerization of difunctional monomers at ambient temperatures[50a,50b,50c,50d]. The new monomers, termed oxy bis-methacrylates for simplicity, are essentially ether-fused dimethacrylates with the ester groups at each end of the molecule. The pendant ester functionality means that this simple aldehyde insertion/condensation reaction can proceed from a wide variety of commercially available acrylate starting materials to provide a series of oxy bis-methacrylate monomers $B$ with a broad range of properties. As shown in Table 4 below, we have investigated the synthesis of these monomers with a number of ester group substituents. The synthesis has been<smiles>[R]OC(=O)C=C</smiles><smiles>O=C(O)COCC(=O)O</smiles><smiles>[R]OC(=O)C(=C)CO</smiles>

A<smiles>[R]OC(=O)C(=C)COCC(=C)C([R])=O</smiles>

B 
Table 4

Product B

Synthesis of Oxy bis-Methacrylate Monomers

Acrylate ester, $R$

Isolated Yield, \&

$\mathrm{mp},{ }^{\circ} \mathrm{C}$

MW

Methyl

67

Ethyl

82

n-Butyl

78

t-Butyl

66

Benzyl

58

Phenethyl

42

Trimethylcyclohexyl

37

$\begin{array}{cc}46-47 & 214 \\ \text { liq. } & 242 \\ \text { liq. } & 298 \\ -22 & 298 \\ 46-47 & 366 \\ 43-44 & 394 \\ 96-97 & 435\end{array}$

optimized with respect to the difunctional monomers although with a change in the reaction conditions, the interesting $\alpha$-hydroxymethyl acrylate compound $A$ can be obtained as the major product.

\section{Cylopolymerization Mechanism}

The cyclopolymerization of oxy bis-methacrylate monomers has been investigated and found to produce polymers with a cyclic ether backbone and pendant ester groups. Under dilute solution polymerzation conditions, the cyclopolymer can be obtained exclusively by an alternating intermolecular 1,2 addition followed by an intramolecular 1,6-cyclization polymerization mechanism ( $P a t h \quad A$ ). In bulk polymerization, which is the relevant mode of polymerization for dental composite materials, these monomers provide crosslinked polymers through a mixture of pathways involving both intramolecular 1,6cycloaddition and intermolecular 1,2-addition polymerization. The 1,2addition between two monomer units which occurs before the internal cyclization (Path B) leaves a pendant "methacrylate-like" group which can subsequently react to yield the crosslink structure.<smiles>[Y][Y](=O)C(=O)OCC(=C)C(=O)O[Na]</smiles><smiles>[Y]C[C](CC)COCC(=C)C(=O)O[R6]</smiles><smiles>[R]CC1(C)COCC(C=[R]OCC)C1</smiles>

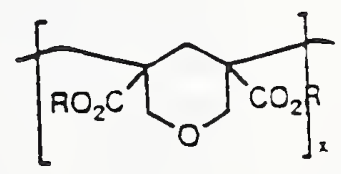<smiles>[3H][13CH2][13CH3]</smiles>

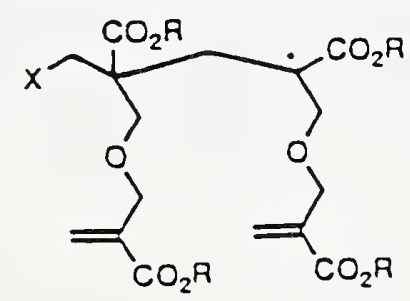

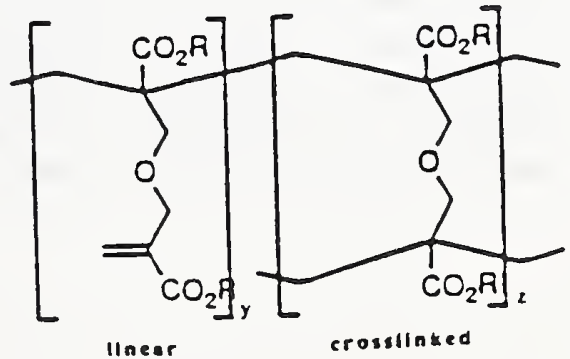


The nature of the ester group was found to have a significant influence on the distribution of these two pathways in the polymerization. Table 5 compares the solution polymer of the ethyl and t-butyl-substituted oxy bis-methacrylate monomers at various concentrations. These were polymers which were stopped at low conversion (prior to crosslinking) so that the ratio of the paths $A$ and $B$ could be determined directly from a ${ }^{1} \mathrm{H}$ NMR analysis of the polymers. As monomer concentration was increased, it is clear that the extent of intermolecular 1,2-addition was also increased. It is further apparent that the monomer with the bulkier t-butyl ester groups utilized the available 1,6cyclopolymerization pathway more efficiently than the less hindered ethyl-substituted monomer. This indicates that the identity of the ester group can be varied to control the degree of crosslinking, which in turn, has a large effect on the overall material properties.

Table 5

\section{Effect of Monomer Concentration on the Solution}

Polymerization of Oxy bis-Methacrylates

Monomer

Concentration, $M$ Wt. $\&$ Time, $h$ Yield, 8 1.2-Addition $\%$

$\mathrm{R}=$ Ethyl
0.5
1.0
1.5
2.0
$\mathrm{R}=$ t-Butyl
0.5
1.0
1.5
2.0

$\mathrm{R}=$ Ethyl

0.5

1.5

2.0

0.5

1.5

2.0
12.1

24.2

36.3

48.4

14.9

29.8

44.7

59.7
4.0

3.0

1. 5

0.8

4. 0

3.0

0.5

0.4
18
15
5
6

21

32

13

6
9
13
18

13

0
trace
4
6

As previously described the base catalyzed reaction of formaladehyde with acrylates can be adapted to prepare highly fluorinated difunctional vinyl monomers and multifunctional oligomers. This synthetic development now makes it possible to prepare these previously unknown monomers from either commercial available fluorinated acrylates or from easily synthesized starting acrylates. Similarly difunctional siloxane monomers and multifunctional oligomers can be prepared.

Applications of the reaction of acrylates via the formaldehyde insertion/condensation were further extended by the preparation of a hydrophobic siloxane oligomer and hydrophilic polyethylene glycol-based oligomers. The multifunctional siloxane oligomer 13 was derived from bis(4-acryloxybutyl) tetramethyldisiloxane. This reaction required the addition of solvent, such as DMSO, and in this regard, was similar to 
the analogous reaction involving highly fluorinated diacrylates [50d]. The siloxane oligomer was obtained as a relatively non-viscous oil which should lead to flexible, crosslinked polymers with high conversion. The water soluble oligomer 14 was prepared from a PEG 400 diacrylate without the addition of any solvent. Unlike the fluorinated oligomers which are primarily composed of 1,4-diene subunits, these new oligomers are similar to the previously prepared alkyl oligomers, such as 15, in which the double bonds are predominantly arranged in a 1,6orientation. This allows for cyclopolymerization, with its reduced degree of polymerization shrinkage, to accompany the usual crosslinking process in the cure of these oligomers as shown schematically wear.<smiles>[Y4]CC(=C)C(=O)OCCC(=C)C(=O)O[Si](C)(C)O[Si](C)(C)COC(=O)C(=C)COCC</smiles>

13
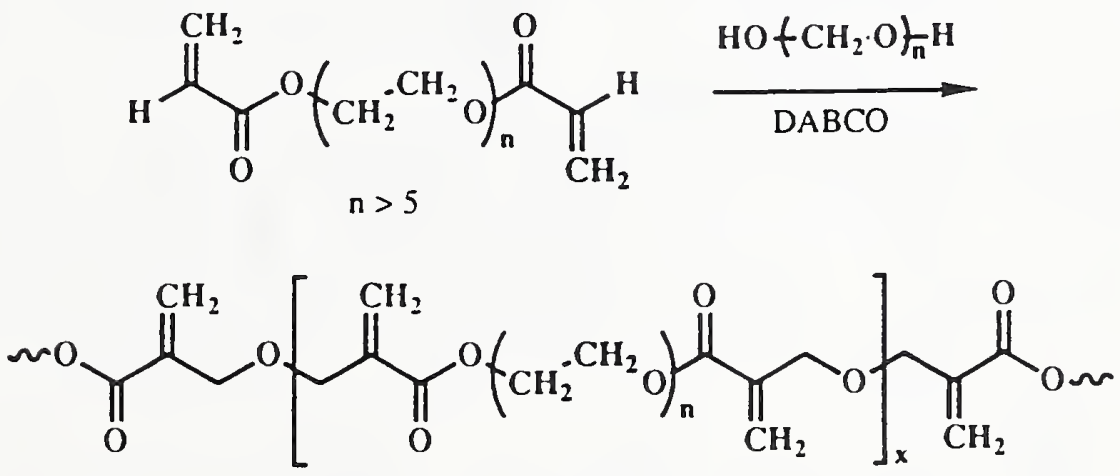

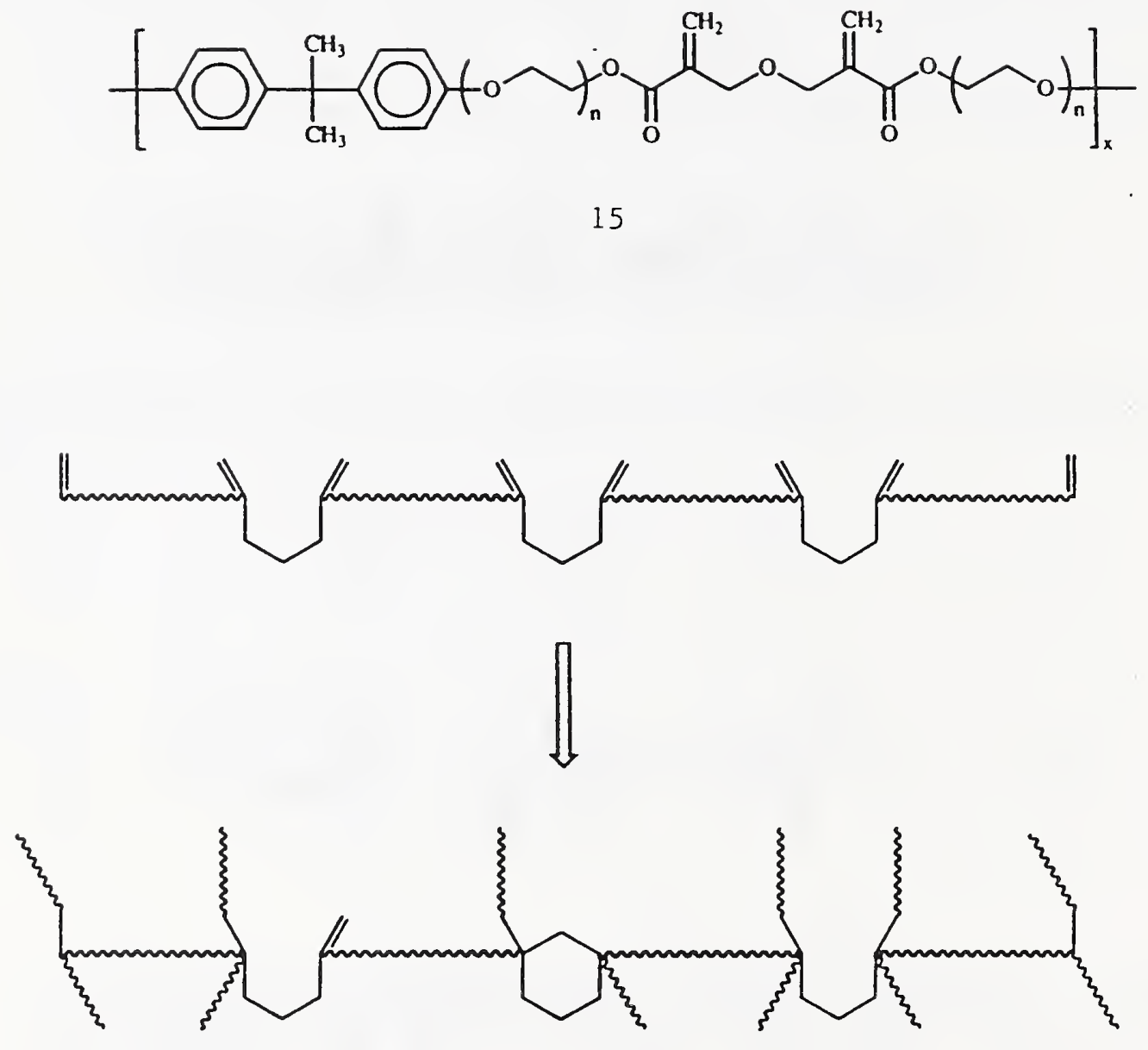

Schematic representation of possible oligomer crosslink formation. 


\section{A.5 Synthesis of Organometallic and Related Monomers}

\section{PROGRESS REPORT}

\section{Background}

The aims of this section of Part I are two fold: (1) to explore the effects of introducing some ionic bonds in the predominantly covalent structure of resin based materials by the inclusion of vinyl metallocarboxylate and related monomers in dental resin systems and (2) to assess the feasibility of introducing radiopacity into composites using heavy atom containing monomers, e.g. zirconyl methacrylates and/or highly brominated aryl monomers.

\section{Accomplishments}

Monomers with the potential to render dental resins radiopaque were synthesized. A radiopaque denture base formulation employing pentabromophenyl methacrylate [75] as a polymerizable radiopaque agent was shown to be color stable and to have gnerally acceptable properties except for the limited solubility of the brominated monomer and a problem with storage stability. The incorporation of pentabromophenyl methacrylate in copolymer form (methyl methacrylate as comonomer) was shown to be an effective method for introducing radiopacity into polymeric dental materials (e.g. denture base) and overcoming the previous shortcomings of this type of denture system. Organometallic methacrylate monomers were synthesized which show promise for use as radiopacifing resins in dental applications. The mechanical strengths of some composites formulated with organometallic resins were comparable to BIS-GMA type resins.

Vinyl metallocarboxylates were prepared from the corresponding dicarboxylic acid monomers [76]. Polysalt multifunctional methacrylates derived from PMDM generally were insoluble in dental monomers (MMA, BIS-GMA, TEGDMA, etc.).<smiles>C=C(C)C(=O)OCCOC(=O)c1cc(C(=O)OCCOC(=O)C(=C)C)c(C(=O)OCCOC(=O)C(=C)C)cc1C(=O)O</smiles>

PMDM poiysalt 
By contrast, many of the vinylmetallocarboxylates derived from monocarboxylic acid vinyl monomers such as MMEP were soluble to some degree in these dental monomers. The zirconium based monomer, ZrO(MMEP $)_{2}$, yielded<smiles>C=C(C)C(=O)OCCOC(=O)c1ccccc1C(=O)[OH2+]</smiles>

MMEP polysalt

organometallic based resin composites with excellent strength and esthetics. In addition, $\mathrm{ZrO}(\mathrm{MMEP})_{2}$ was effective in introducing or augmenting the radiopacity of both composites and denture base materials. Depending on the type of vinyl metallocarboxylate these types of monomers also may have application as adhesion promotors and as catalysts for certain redox initiator systems [77].

\section{A.6 Effect of Post Cure Storage Time on the Properties of Composites}

(New project-a cooperative study with Dr. T.J. Matthews of Howard University and Dr. W.G. De Rijk of the University of Texas at San Antonio).

\section{Background}

Previous studies have indicated a direct relationship between the storage time and temperature and the degree of cure and certain other properties of resin based dental composites [78-80]. In a more recent study the time dependency of the diametral tensile strength of a visible light cured for time intervals of $5,15,30,60$ and 1440 (24h) minutes, experimental BIS-GMA composite stored in air at $22^{\circ} \mathrm{C}$ was evaluated using Weibull statistical analysis [81]. In that study it was shown that the Weibull modulus, $m$, was virtually independent of storage time and that the characteristics strength, $S_{0}$, showed small, but significant increase between 5 and 30 minutes, virtually no increase between 30 minutes and one hour, and a much larger increase between 1 hour and 24 hours.

\section{PROGRESS REPORT}

Phase I

In a continuation of this Weibull study, the effect of post cure storage time $(T)$ on DTS of the same experimental visible light activated composite was evaluated from specimens stored at $37^{\circ} \mathrm{C}$ in distilled water for the same time intervals used in the previous study. Approximately 20 specimens for each storage interval were prepared and 
fractured at a crosslead speed of $10 \mathrm{~mm} / \mathrm{min}$. The composition of the composite on a weight percent basis was as follows: the resin was 17.78, consisting of 69.78 BIS-GMA, 29.38 TEGDMA, 0.88 ethyl $4-$ dimethylaminobenzoate and 0.28 camphorquinone, while the filler component was 83.38 , comprising a silanized $(0.58$ A-174) barium oxide silica glass with an average particle size of $44 \mu \mathrm{m}$. For each time interval the $\mathrm{S}_{0}$ for the $37^{\circ} \mathrm{C}$ stored specimens was higher compared to those stored at $22^{\circ} \mathrm{C}$. The $\mathrm{m}$ value for the $37^{\circ} \mathrm{C}$ study showed some fluctuation with $T$ while all the $S_{0}$ values, except those for 30 minutes and one hour, showed significant increases with $T$ at 958 confidence level. An abstract based on this work has been submitted for the 1991 IADR meeting.

\section{A. 7 Initiator Systems}

\section{PROGRESS REPORT}

\section{Background}

There is a need to improve the effectiveness of currently used dental resin initiator systems and develop new systems for enhanced conversion, depth of cure and color stability of dental sealant and composite materials.

\section{Accomplishments}

Some of the parameters involved in visible light polymerization of dental resins using camphorquinone and tertiary amines were identified [71a,71b]. Generally camphorquinone-tertiary aryl amines photoinitiator systems gave higher degrees of cure and greater depths of cure than similar photoinitiator systems based on tertiary aliphatic amines. The color stabilities of the cured resins containing tertiary aliphatic amines were generally better than those formulated with tertiary aryl amines. Sterically hindered cycloaliphatic tertiary amines of the type used to stabilize polymers against oxidation gave cured polymers with the best color stabilities and better than average conversions.

A related study demonstrated that salts and complexes of tertiary amines still function as efficient activators in photochemical (e.g. camphorquinone, $C Q$ ) and chemical (e.g. benzoyl peroxide, BPO) initiator systems provided fast-polymerizing dental resins (e.g. BIS-GMA, urethane methacrylates) are used [71a]. Generally, composites derived from formulations using the amine salts or complexes had excellent esthetics and color stabilities and had diametral tensile strengths similar to composites derived from the corresponding formulations containing equivalent amounts of the free amines. With slower polymerizing monomers (e.g. MMA) containing BPO, the salt or complex derivatives of the tertiary amines were inferior to the free amine as a polymerization accelerator, yielding slow setting formulations that often became highly colored. 
A new project related to our work on resin-modified glass ionomer cements and bonding to dentin involved the use of sodium $p$-toluene sulfinate and related salts as components of free radical initiator systems. Effective dual cures (free radical and ionic acid-base reactions) were obtained with a modified water hardening glass ionomer cement (Chemfil II). The powder contained either benzoyl peroxide (BPO) or the t-butyl perester of maleic acid (TBMA) while the water had dissolved sulfinate salt. In the case of the BPO-sulfinate initiator system no tertiary aromatic amine is need since the polyacid converts the sulfinate salt to the reactive $p$-toluene sulfinic acid. The same mechanism presumably is involved in the generation of initiating radicals from the TBMA-sulfinate initiator system. TBMA, itself, is capable of converting sulfinates such as sodium $p$-toluene sulfinate to the reactive sulfinic acid form as shown by the fast setting at ambient temperatures of BIS-GMA/HEMA resins using this initiator system.

B. Improvement of Filler Systems for Composites and Cements

\section{PROGRESS REPORT}

\section{Background}

Considerable effort has been given to improving the properties (especially wear resistance and polishability) of dental composites through modification of their filler systems. Microfilled, small and submicron macrofilled, hybrid filled and megafilled inserts composites have been developed. There also has been a trend toward somewhat softer fillers that would not abrade opposing enamel or accelerate the wear process. Modifications in the surface porosity of fillers as a means of enhancing interfacial bonding and wear resistance is another significant development.

The basic approach of this proposal is to optimize the properties of composites by controlling the type, size, shape, distribution and volume percent of the dispersed phase. In addition to the traditional siliceous fillers (radiopaque glasses, fused quartz, silicates, mica, microfine silicas) emphasis is given to other softer, more ductile filler types such as, various phosphates, metaphosphates, polymers, etc. as candidates for use in the filler phase of these materials.

\section{Accomplishments}

Results to date indicate that the metaphosphates offer promise as an alternate or supplementary filler component for dental composites [82]. Depending on the preparative conditions various crystalline forms of calcium metaphosphate and a vitreous form were made from monocalcium phosphate or its hydrate by the reaction shown below:

$$
\mathrm{Ca}\left(\mathrm{H}_{2} \mathrm{PO}_{4}\right)_{2} \cdot \mathrm{H}_{2} \mathrm{O} \stackrel{150^{\circ} \mathrm{C}}{\longrightarrow} \mathrm{Ca}\left(\mathrm{H}_{2} \mathrm{PO}_{4}\right)_{2}+\mathrm{H}_{2} \mathrm{O}
$$


$\mathrm{Ca}\left(\mathrm{H}_{2} \mathrm{PO}_{4}\right)_{2} \stackrel{250-950^{\circ} \mathrm{C}}{\longrightarrow} \quad \mathrm{Ca}\left(\mathrm{PO}_{3}\right)_{2}+2 \mathrm{H}_{2} \mathrm{O}$

of the four crystalline forms $(\alpha, \beta, \gamma, \delta)$ the least soluble crystalline form is $\beta-\mathrm{Ca}\left(\mathrm{PO}_{3}\right)_{2}$; of these calcium metaphosphates the vitreous form has the greatest solubility. Composites made from the latter become highly swollen on storage in water at $37^{\circ} \mathrm{C}$. Visible light activated composites using untreated and treated $\beta-\mathrm{Ca}\left(\mathrm{PO}_{3}\right)_{2}$ were prepared. The untreated filler gave composites with strengths similar to those obtained with untreated glass macrofillers. Composites made with $\beta$ $\mathrm{Ca}\left(\mathrm{PO}_{3}\right)_{2}$ treated with zirconyl dimethacrylate had diametral tensile strengths (DTS) of almost $34 \mathrm{MPa}$, excellent esthetics and were unchanged in appearance after 1 year at $37^{\circ} \mathrm{C}$ in water. Hybrid composites made with both silanized glass and treated $\mathrm{Ca}\left(\mathrm{PO}_{3}\right)_{2}$ had excellent strength. In addition to its favorable index of refraction, $\beta-\mathrm{Ca}\left(\mathrm{PO}_{3}\right)_{2}$ is non-toxic, has low solubility, can be easily milled, possesses a soft non-abrasive, polishable texture and resembles natural teeth in color and esthetics. A patent application based on this work is in progress and a paper has been prepared and accepted for publication in Dental Materials.

\section{Improvement of Interfacial Bonding Systems}

\section{PROGRESS REPORT}

\section{Background}

The weakest link in silane treated siliceous composites is the oxane bond that forms between the silane agent and the silanol groups on the filler surface. The oxane bond that forms between the coupling agent (e.g. A-174) and the mineral phase is vulnerable to hydrolysis, especially if it is not completely formed [83]. The extent of copolymerization of the resin system with the coupling agent also is an important factor in determining the durability of the interphase. The objective of this section is to develop coupling agents and methods of surface modification that will improve the quality of the interfacial bonding phase in composites and thereby enhance their durability.

\section{Accomplishments}

Our work with the traditional silane agent, 3-methacryloxypropyltrimethoxysilane $(A-174)$ and similar silane agents indicated the potential vulnerability of this interfacial bonding agent to hydrolytic degradation or debonding (boil test). The multifunctional silane agent we prepared from BIS-GMA and 3-isocyanatopropyltriethoxysilane performed much better under such a test [84].

In addition, we evaluated a number of other commercial silane agents, organotitanates and organozirconates [85]. The methacryl containing coupling agents all gave positive indications of interfacial adhesion to glass fillers but the methacryl silanes out performed the methacryl titanates and zirconates as measured by the diametral tensile strength 
test. An experimental organoaluminate also was prepared and evaluated as a coupling agent; it exhibited significant, but modest bonding to glass fillers. $\quad \beta-\mathrm{Ca}\left(\mathrm{PO}_{3}\right)_{3}$ treated with zirconyl dimethacrylate exhibited superior interfacial bonding in composites compared to A-174 or PMDM treated $\beta-\mathrm{Ca}\left(\mathrm{PO}_{3}\right)_{2}[82]$.

The 3- or 4-point transverse and uniaxial tensile tests which have been shown to be a more sensitive mechanical test than the diametral tensile strength measurement for evaluating interfacial coupling agents will be used in future studies [84].

D. New Resin Systems and Pretreatment Techniques for Bonding to Dentin

\section{PROGRESS REPORT}

\section{Background}

Current dental composites, in contrast to polycarboxylate and glass ionomer cements, are not inherently adhesive to enamel or dentin. The discovery of the acid etch pretreatment technique by Buonocore, however, provided an effective means of bonding composites to enamel $[49,50]$.

The generation of surface microporosities in enamel by acid treatments involving both inorganic $\left(\mathrm{H}_{3} \mathrm{PO}_{4}, \mathrm{HNO}_{3}\right)$ and organic acids (citric, pyruvic) permits infiltration of the resin into this substrate which by polymerization then forms a micromechanical, interlocking, tag-like structure with the enamel. Although an element of chemical bonding also may exist with certain bonding resins than contain acid (e.g. Phenyl-P, PMDM), anhydride (e.g. 4-META), chelating (e.g. NPG-GMA), or other types of surface-active groups, the primary mode of adhesion to enamel is considered to be by micromechanical retention. However, superior tag formation and perhaps some chemical interaction may develop when certain types of surface-active components are used in the resin bonding system.

Because of its vital and heterogenerous nature, bonding to dentin has been a more challenging problem. On a weight basis dentin consists of 698 apatitic mineral (mainly hydroxyapatite), $18 \%$ organic matter (mainly collagen) and 138 water. Factors that can adversely affect bonding to dentin include an inherently wet, tubular surface structure that provides a variable area of peritubular and intertubular dentin. In addition, other complications that can adversely effect bonding include an ill-defined smear layer, which contains damaged dentin having denatured collagen and an altered mineral phase, and the potential for intertubular dentinal fluid flow to the bonded interface which may compromise the durability of the original bond to dentinal tissue.

Although many bonding systems for dentin are predicated on chemical reactions involving the mineral and/or organic components of dentin with surface-active agents (e.g. monomer, polymer, components of the 
initiator system, etc.), the prevailing assessment indicates that a strong micromechanical, interlocking mode of bonding is involved[5563]. In addition, in some systems, the polymerization mechanism, e.g. by initiation primarily from the dentinal substrate, may play an important role, especially in those systems (e.g. PMDM) that involve some sort of spontaneous polymerization and/or efficient oxygen scavenging reactions. A major objective of our studies has been to obtain a better understanding of all phases of the mechanisms for bonding to dentin which would aid in the design of more effective, durable bonding systems. Other objectives are to synthesize new types of surface active monomers, initiator systems or other agents for improving interaction with dentin and to assess the efficacy of new modes of pretreating dentin.

\section{Accomplishments}

oligomers containing pendant isocyanate groups were prepared by copolymerization of two types of isocyanto monomers, isocyanatoethyl methacrylate (IEM) and $m$-isopropenyl- $\alpha, \alpha$-dimethylbenzyl isocyanate (TMI), with a variety of vinyl monomers. When used with glutaraldehyde treated dentin or bone these oligomers displayed significant adhesion to these substrates. Bonding to soft tissue substrates also was feasible.

The diadduct of benzophenone tetracarboxylic dianhydride and $\mathrm{N}-\mathrm{t}$ butylaminoethyl methacrylate (BTDA-TBAEM) was synthesized and characterized. It was shown to have some photoactive properties. Preliminary tests of solutions of this monomer in HEMA exhibited significant adhesion to dentin that had been treated with ferric/oxalate/N-phenylglycine according to the Bowen bonding procedure.<smiles>C=C(C)C(=O)OCCN(C)C(=O)c1cc(C(=O)c2ccc(C(=O)O)c(C(=O)N(C)CCOC(=O)C(=C)C)c2)ccc1C(=O)O</smiles>

BTDA-TBAL:M

Formulation of carboxylic acid-containing monomers for bonding to tooth structure (new project with Dr. G.E. Schmacher of NIH and Dr. F. Eichmiller of the American Dental Association Health Foundation/Paffenbarger Research Center (ADAHF/PRC). 


\section{PROGRESS REPORT}

Phase I

Several effective bonding systems based on PMDM have been developed (55c,59,61-63). PMDM, a high melting solid, has very limited solubility in many solvents and monomers. It can be dissolved in acetone and it is from this solvent that it is usually applied to conditioned dentin surfaces as a surface-active monomer or primer for bonding composites to resin based materials. In this study the feasibility of applying a primer based on mono(2-methacryloyloxy) ethyl phthalate (MMEP), a monofunctional liquid homolog of PMDM, was explored. Dentin surfaces were pretreated sequentilly with $0.88 \mathrm{w} / \mathrm{w}$ ferric oxalate in $2.58 \mathrm{w} / \mathrm{w} \mathrm{HNO}_{3}$, (2) $108 \mathrm{w} / \mathrm{w} \mathrm{N}$-phenylglycine in acetone and (3) the experimental primer before applying a chemically activated composite (ADAPTIC). The tensile bond strengths were tested after $24 \mathrm{~h}$ of storage in distilled water at $24^{\circ} \mathrm{C}$ using a crosshead speed of 5 $\mathrm{mm} / \mathrm{min}$. Two types of primers or bonding resins were used in step (3), theose formulated with acetone as the liquid vehicle for the primer and those fomulated with only resins as shown below. The vertical lines indicate nonsignificant differences between groups by Duncan's Multiple Rank test at the 958 confidence interval. The number of specimens, $n$, tested was 10 .

Composition of Bonding Resin in $8 \mathrm{w} / \mathrm{w}$

I $\quad 33.4$ MMEP, 7.2 PMDM, 59.4 HEMA

II 38.2 MMEP, 45.8 BIS-GMA, 16.0 HEMA

$\begin{array}{cc}\text { TBS }(\mathrm{MPa}) & \text { S.D. } \\ 10.5 & 3.7 \\ 9.4 & 3.0 \\ 7.9 & 3.7 \\ 7.5 & 1.4 \\ 6.9 & 2.5 \\ 5.9 & 2.4 \\ 5.3 & 2.4 \\ 1.7 & 1.6 \\ 0.8 & 1.3\end{array}$

III $10.0 \mathrm{PMDM}$ in acetone (control)

IV $11.6 \mathrm{MMEP}$ in acetone

$\mathrm{V} \quad 5.8$ MMEP in acetone

VI 23.2 MMEP in acetone

VII 70.0 MMEP, 30.0 TEGDMA

VIII 100 MMEP

IX No bonding resin

1.7

1.3

The above results suggest that MMEP in monomeric solution or when applied from acetone can effectively promote bonding to dentin. The use of MMEP and PMDM in the hydrophilic monomex HEMA seems to be especially effective. Further studies on MMEP based bonding systems are planned. An abstract based on this work has been submitted and accepted for the 1991 IADR meeting.

\section{E. Improvement of Dental Cements}

\section{PROGRESS REPORT}

\section{Background}

Dental cements also can be considered as composite materials and because of their heterogenous nature exhibit many of the same problems, i.e. relatively weak matrices, fillers and interphases that are vulnerable to mechanical, physical or chemical modes of degradation 
[86-96]. Dental cements are especially weak in their resistance to acidic conditions and the tensile and shear forces that are commonly generated by masticatory activities and stresses.

Dental cements can be divided into two broad categories: (1) those that are largely aqueous based (e.g. zinc phosphate, zinc polycarboxylate and glass ionomer cements) and (2) those that are relatively nonaqueous in nature, although small amounts of water or other protic agents are considered essential to their setting and hardening process (e.g. ZOE, ZOE-EBA, HV-EBA, and dimer acid cements). Dental cements that combine optimal strength, adhesion, durability and biocompatibility are still lacking.

The goal of this research is to improve dental cements by appropriate changes in the chemical structures of their matrices. These changes are designed to reduce their propensity for brittle failure and hydrolytic degradation and, concomitantly, enhance their adhesion to tooth structure as well as their biocompatibility.

\section{Accomplishments}

Hybrid Cement-Composites Based on Glass Ionomer Cements

Hybrid cement-composites based on glass ionomer cements also were prepared and evaluated. One type was based on the use of compatible, in situ radical curable monomer systems [92]. A second type employed water soluble polymers and a third was a combination (monomer/polymer) version of the first two hybrid cement-composites [93]. These types of resin and/or polymer-modified glass ionomer cements exhibit far less propensity to brittle failure, are less sensitive to moisture during setting and to dehydration after setting, and are not as vulnerable to erosion in acidic media. During pin-on-disc wear studies none of the resin-modified glass ionomer cements failed catastrophically as often occurred with the conventional cements. Using the composite-glass ionomer sandwich technique for bonding to dentin, the resin-modified glass ionomer did not require prior etching or the use of intermediary bonding agents and showed excellent resistance to microleakage. Generally, the modified glass ionomers gave about the same tensile adhesion strengths to dentin as the unmodified cement but their adhesion to composites (without prior etching) was superior [94].

Polymeric Calcium Phosphate Cements

A series of new polymeric calcium phosphate cements was developed $[95,96]$ based on the ambient setting reaction of tetracalcium phosphate and dicalcium phosphate in various types of aqueous solutions: aqueous solutions containing in situ radical curable monomer systems, (2) in aqueous solutions of polymers, and (3) aqueous solutions of resins plus polymers. In some of these aqueous solutions (e.g. gelatin, polyvinyl alcohol) significant conversion to hydroxyapatite occurred in the set cement. Polyelectrolyte cements, e.g. those based 
on polyacrylic or its copolymers, gave fast setting, strong cements that show modest, but significant adhesion to dentin [96]. 
References

[1] Bowen, R.L. Use of epoxy resins in restorative materials. J. Dent. Res. 35: 360-369, 1956.

[2] Bowen, R.L. Dental filling materials comprising vinyl silane treated fused silica and a binder consisting of the reaction products of bisphenol and glycidyl methacrylate, U.S. Patent 3,066,012, 1962.

[3] Bowen, R.L. Properties of a silica-reinforced polymer for dental restorations, J. Am. Dent. Assoc. 66:57-64, 1963.

[4] Bowen, R.L. Effect of particle shape and size distribution in a reinforced polymer, J. Am. Dent. 69:481-495, 1964.

[5] Antonucci, J.M. New monomers for use in dentistry. In: Biomed. and Dental Applications of Polymers eds., Gebelein, C.G. and Koblitz, F.F. Plenum Press, NY, NY, 357-371, 1981.

[6] Jorgensen, K.D. and Asmussen, E. Occlusal abrasion of a composite restorative material with ultra-fine filler - An initial study. Quintessence Int. 9:73-78, 1978.

[7] Dennison, J.B. Status report on microfilled composite restorative resins. J. Am. Dent. Assoc. 105:488-492, 1982.

[8] Glenn, J.F. Composition and properties of unfilled and composite resin restorative materials. In: Biocompatibility of Dental Materials Vol. 3, Smith, D.C. and Williams, D.F. eds, CRC Press, Boca Raton, FL Pp. $97-130,1982$.

[9] Lutz, F. and Phillips, R.W. A classification and evaluation of composite resin system. J. Prosth. Dent. 50:480-488, 1983.

[10] Cook, W.D., Beech, D.R., and Tyas, M.J. Structure and properties of methacrylate based restorative materials. Biomaterials 6:362-368, 1985 .

[11] Draughn, R.A., Bowen, R.L. and Moffa, J.P. Composite restorative materials. In: Restorative Dental Materials An Overview, Vol. 1, J.A. Reese and T. Valega, eds., Londone: Quintessence Publishing Co. Ltd., pp. 75-107, 1985 .

[12] Antonucci, J.M. Resin Based Dental Composites-An Overview. In: Polymers in Medicine II, Chiellini, E., Giusti, P., Migliaresi, C. and Nicolais, L. eds., New York: Plenum Publishing Corp., pp. 277-303, 1986. 
[13] Draughn, R.A. Fatigue and fracture mechanics of composite resins. In: Posterior Composite Resin Dental Restorative Materials, VanHerle, G. and D.C. Smith, eds., Peter Szulc Publishing Co., The Netherlands, pp. $29-307,1985$.

[14] McCabe, J.F. In vitro wear testing of composite resins ibid. pp. 319 $330,1985$.

[15] McKinney, J.E. Enivronmental damage and wear of dental composite restoratives. ibid pp. $331-347$.

[16] Ruyter, I.E. Monomer systems and polymerization ibid pp. 109-135, 1985.

[17] Soderholm, K-J. Filler systems and resin interface ibid pp. 139-159, 1985.

[18] Cook, W.P. Polymerization defects in composite resins ibid pp. 273286, (1985).

[19] Fan, P.L. Polymerization defects ibid pp. 287-298.

[20] Davidson, C.L. Conflicting interests with posterior use of composite materials. ibid pp. 61-65, 1985.

[21] Bowen, R.L., Menis, D.L., Setz, L.E., and Jennings, K.A. Theory of Polymer Composites ibid pp. 95-1051, 1985.

[22] Craig, R.G. Overview of posterior composite resins for use in clinical practice ibid pp. 199-211, 1985.

[23] Erickson, R.L. Closing remarks ibid pp. 555-557, 1985.

[24] Leinfelder, K.F. Current developments in posterior composite resins. In: Advances in Dental Research 2(1) International State-of-the-Art Conference on Restorative Dental Materials 1986, NIDR 15-121, 1988.

[25] Ruyter, I.E. Composites-characterization of composite filling materials: Reactor response, ibid, 122-129, 1988.

[26] Asmussen, E. Composite restorative resins: Composition versus wallto-wall polymerization contraction, Acta. Odont. Scand. 33:337-344, 1975.

[27] Dermann, K., Rupp, N.W., and Brauer, G.M. Effect of hydrophilic diluents on the properties of cured composites, J. Dent. Res. 61:1250$1254,1982$.

[28] Brauer, G.M., Dulik, D.M., Hughes, H.N., Dermann, K., and Rupp, N.W. Marginal adaptation of BIS-GMA-based composites containg various diluents, J. Dent. Res. 60:1966-1971, 1981. 
[29] Bowen, R.L., Rapson, J.E., and Dickson, G. Hardening shrinkage and hygroscopic expansion of composite resins. J. Dent. Res. 61, 654-658, 1982 .

[30] Thompson, V.P., Williams, E.F., and Bailey, W.J. Dental resins with reduced shrinkage during hardening, J. Dent. Res. 58:1522-1532, 1979.

[31] Endo, T. and Bailey, W.J. Synthesis and radical ring-opening polymerization of spiro o-carbonates, J. Polym. Sci.: Polym. Chem. Ed. $13: 2525-2530,1975$.

[32] Stansbury, J.W. and Bailey, W.J. Evaluation of spiro orthocarbonate monomers capable of polymerization with expansion as ingredients in dental composite materials. In: Progress in Biomedical Polymers, C.G. Gebelein and R.L. Dunn, eds., Plenum Pub. Corp., New York, pp. 133-139, 1990 .

[33] Bausch, J.R., De Lange, K., Davidson, C.L., Peters, A., and De Gee A.J. Clinical significance of polymerization shrinkage of composite resins. J. Prosthet. Dent. 48, 59-67, 1982 .

[34] Bowen, R.L., Nemoto, K., and Rapson, J.E. Adhesive bonding of various materials to hard tooth tissues; forces developing in composite materials during hardening. J. Am. Dent. Assoc. 106, 475-477, 1983.

[35] Kidd, E.A.M. Polymerization shrinkage and microleakage. In: Posterior Composite Resin Dental Restorative Materials, G. VanHerle and D.C. Smith, eds., Peter Szulc Pub. Co., The Netherlands pp. 263-268, 1985.

[36] Patel, M.P., Braden, M., and Davy, K.W.M. Polymerization shrinkage of methacrylate esters, Biomaterials 8:53-56, 1987.

[37] Rees, J.S. and Jacobsen, P.H. The polymerization shrinkage of composite resins, Dent. Mater. 5:41-44, 1989.

[38] Feilzer, A.J., DeGee, A.J., and Davidson, C.L. Setting stress in composite resin in relation to configuration of the restoration, $J$. Dent. Res. 66:1636-1639, 1987.

[39] Antonucci, J.M., Stansbury, J.W., and Dudderar, D.J. Dental resin and initiator systems based on polythiols. J. Dent. Res. 61 270, Abst. 824, 1982 .

[40] Venz, S. and Antonucci, J.M. Effect of a polythiol on the degree of polymerization of resins. J. Dent. Res. 63 199, Abst. 257, 1984.

[41] Antonucci, J.M. Dental Composite Formulation from acrylate monomer and monomer polythiol accelerator. U.S. Patent 4,536,523, 1985. 
[42] Asmussen, E. Restorative resins: hardness and strength vs. quantity of remaining double bonds, Scand. J. Dent. Res. 90:484-489, 1982.

[43] Ferracane, J.L. and Greener, E.H. The effect of resin formulation on the degree of conversion and mechanical properties of dental restorative resins, J. Biomed. Mater. Res. 20:121-131, 1986.

[44] McKinney, J.E. and Wu, W.L. Effect of degree of cure on hardness and wear of three commercial dental composites, J. Dent. Res. 62:285, Abstr. No. 1047, 1983.

[45] Asmussen, E. Factors affecting the color stability of restorative resins, Acta. Odont. Scand. 41:11-18, 1983.

[46] De Rijk, W.G., Conner, M.L., Jennings, K.A., and Wu, W. The in vivo wear resistance of dental composites with enhanced polymerization. J. Dent. Res. 63:286 Abst 951, 1983.

[47] Antonucci, J.M., Stansbury, J.W. and Venz, S. Synthesis and properties of a polyfluorinated prepolymer multifunctional urethane methacrylate. Poly. Mater. Sci. Eng., Proceeding of the ACS Division of Polymeric Materials Vol. 59, pp. 388-396, 1988.

[48] Antonucci, J.M., Venz, S., Stansbury, J.W. and Dudderar, D.J. Low surface energy dental composites from a polyfluorinated prepolymer multifunctional methacrylate. Proceedings of the 1st Medical Plastic Conference of the Society of the Plastic Industry, Inc. New Brunswick, NJ , 1983.

[49a] Buoncore, M.G. A simple method of increasing the adhesion of acrylic filling materials to enamel surfaces. J. Dent. Res. 34:849-853, 1955.

[49b] Buoncore, M.G., Wileman, W. and Brudevold, F. A report on a resin composition capable of bonding to human dentin surfaces. J. Dent. Res. $35: 846-851,1956$.

[50a] Mathias, L.J., Kusefoglu, S.H., and Ingram, J.E. Cyclopolymerization of the ether of methyl- $\alpha$-(hydroxymethyl)acrylate, Macromolecules $21: 545-546,1988$.

[50b] Stansbury, J.W. Cyclopolymerizable monomers for use in dental resin composites. J. Dent. Res. 69:844-848, 1990.

[50c] Stansbury, J.W. Evaluation of a new multifunctional oligomer for dental composites. J. Dent. Res. 69 Abstr. 794, 1990.

[50d] Antonucci, J.M., Stansbury, J.W. and Cheng, G.W. A facile synthesis of novel fluorinated multifunctional acrylates. Polymer Preprints 31(1) $320-321,1990$.

[51] Ferracane, J.L. In vitro evaluation of composite resins. Trans. Acad. Dent. Materials 2(2) 6-35, 1989. 
[52] Cross, M., Douglas, W.H. and Fields, R.P. The relationship between filler loading and particle size distribution in composite resin technology. J. Dent. Res. 62, 850, 1983.

[53] Nemcek, J., Roberts, T.A., and Sherliker, F.R. U.S. Patent 4,374,937.

[54] Donly, K.J., Wild, T.W., Bowen, R.L. and Jensen, M.E. An in vitro investigation of the effects of glass inserts on the effective composite resin polymerization shrinkage. J. Dent. Res. 68, 1234-1237, 1989 .

[55a] Asmussen, E. and Munksgaard, E.C. Adhesion of restorative resins to dentinal tissue ibid pp. 217-229, 1985.

[55b] Beech, D.R. Bonding of restorative resins to dentin ibid pp. 231-238, 1985.

[55c] Bowen, R.L., Cobb, E.N. and Rapson, J.E. Adhesive bonding of various materials to hard tooth tissues: Improvement in bond strength to dentin, J. Dent. Res. 61;1070-1076, 1982.

[56] Asmussen, E. and Munksgaard, E.C. Bonding of restorative resins to dentin promoted by aqueous mixtures of aldehydes and active monomers. Int. Dent. J. 35:160-165, 1985 .

[57] Nakabayashi, N., Kojima, K., Masuhara, E. The promotion of adhesion by the infiltration of monomers into tooth substrates. J. Biomed. Mater. Res. 16:265-273, 1982 .

[58] Phillips, R.W. Bonding agents and adhesives. In: Advances in Dental Research 291) International State-of-the-Art Conference on Restorative Dental Materials (1986, NIDR) 150-154, 1988.

[59] Bowen, R.L. Bonding agents and adhesives; Reactor Response ibid 150157,1988 .

[60] Fusayama, T. The problems preventing progress in adhesive restorative dentistry, ibid $158-161,1988$.

[61] Asmussen, E., DeAraujo, P.A., and Peutzfeld, A. In-vitro bonding of resins to enamel and dentin. An Update, Trans. Acad. Dent. Materials 2(2) pp. $36-63,1989$.

[62] Erickson, R.L. Adhesive dental materials, Trans. International Congress of Dental Materials (Acad of Dent. Materials and the Japanese Soc. for Dental Materials and Devices) Okabe, T. and Takahashi, S. eds. pp. 55-69, 1989 .

[63] Nakabayashi, N. Adhesive Dental Materials, ibid pp. 70-79, 1989. 
[64] Hoffman, H.M.R. and Rabe, J. Synthesis and biological activity of $\alpha$ methylene-r-butyrolactones, Angew. Chem. Int. Ed. Engl. 24:94-110.

[65] Petragnani, N., Ferraz, H.M.C., and Silva, G.V.J. Advances in the synthesis of $\alpha$-methylene lactones, Synthesis 1986:157-183, 1986.

[66] Akkapeddi, M.K. Poly( $\alpha$-methylene- $\boldsymbol{\gamma}$-butyrolactone); synthesis, configuration structure and properties, Macromolecules 12:546-551, 1979 .

[67] Akkapeddi, M.K. The free radical copolymerization of $\alpha$-methylene- $\gamma$ butyrolactone, Polymer 20:1215-1216, 1979 .

[68] Ueda, M., Takahashi, M., and Pittman, C.U. Radical-initiated homo- and copolymerization of $\alpha$-methylene- $\gamma$-butyrolactone, J. Polym. Sci.: Polym. Chem. Ed. 20:2819-2828, 1982 .

[69] Stansbury, J.W. and Antonucci, J.M. Evaluation of $\alpha$-methylene- $\gamma$ butyrolactone as a monomer in dental resin formulations. J. Dent. Res. 66 Abstr. 1116, 1987.

[70] Venz, S., and Antonucci, J.M. Physical and chemical characteristics of dual-cured dental composites. IADR, March, 1988, J. Dent. Res. 67 Abst. No. 901.

[71a] Antonucci, J.M. and Venz, S. Tertiary amine salts and complexes as chemical and photochemical accelerators. J. Dent. Res. 66:128, Abst. No. $170,1987$.

[71b] Venz, S., and Antonucci, J.M. Effect of photoaccelerators on curing and discoloration of composites. J. Dent. Res. 66:246, Abst. 1113, 1988.

[72] McKinney, J.E., Antonucci, J.M. and Venz, S. In vitro performance of a dual-cured experimental composite containing a hydrophobic, flexible polymer matrix. IADR, March 1988, J. Dent. Res. 67 Abst. No. 1188.

[73] Butler, G.B. Perspectives in cyclopolymerization. In: Proceedings of the International Symposium on Macromolecules, E.B. Mano, ed., Elsevier Scientific Publishing Co., Pp. 57-76, 1975.

[74] Marvel, C.S. Intramolecular-intermolecular polymerization of nonconjugated diolefins, J. Polym. Sci. 48:101-108, 1960.

[75] Brauer, G.M., Steingerger, D.R. and Stansbury, J.W. Modified radiopaque bone cement with low exotherms. Biomaterials 84 Transactions Vol. 7 p. 347.

[76] Antonucci, J.M., Stansbury, J.W. and Fowler, B.0. Synthesis of multivalent metal dicarboxylate monomers. J. Dent. Res. 68, Abst. 1176, 1989. 
[77] Antonucci, J.M., Stansbury, J.W., Fowler, B.O. and Eichmiller, F. Monomer systems based on multivalent metal monocarboxylate monomers. J. Dent. Res. 69:208 Abst. 793, 1990.

[78] Baush, J.R., De Lange, C. and Davidson, C.L. The influence of temperature on some physical properties of dental composites. Oral Rehabil. 8, 309-317, 1981.

[79] Leung, R.L., Fan, P.L. and Johnston, W.M. Post-irradiation polymerization visible light-activated composite resin. J. Dent. Res. $62,363-365,1983 a$.

[80] Leung, R.L., Adishian, S.R. and Fan, P.L. Comparison of postirradiation polymerization of photoactivated composite resins. J. Dent. Res. 62, Abst 446, 1983.

[81] Matthews, T.J., Antonucci, J.M. and De Rijk, W.G. The effect of postcure storage time on the diametral tensile strength of composites. J. Dent. Res. 69 Abst 988, 1990.

[82] Antonucci, J.M., Fowler, B.O. and Venz, S. Filler systems based on calcium metaphosphates. J. Dent. Res. 67 Abst. No. 869, 1988.

[83] Raney, M.W., Berger, S.E. and Marsden, J.G. Silane coupling agents in particulate mineral filled composites. Interfaces in polymer matrix composites In: Composite Materials 6, Plueddemann, E.P., ed. Academic Press, New York, N.Y., 1974.

[84] Venz, S. and Antonucci, J.M. Silanization and modification of fillers for dental composites. J. Dent. Res. 65 Abst. No. 191, 1986.

[85] Strassler, H.E., Antonucci, J.M. and Marsh, J. Organozirconates as coupling agents for glass filled dental composites. J. Dent. Res. $69: 232$ Abst $987,1990$.

[86] Wilson, A.D. Dental cements - general. In: Scientific Aspects of Dental Materials von Fraunhofer, J.A. and Bradlaw, R. eds, Boston Buttersworth pp. 131-158, 1975.

[87] Wilson, A.D. The chemistry of dental cements Chem. Soc. Rev. 7265 , 1978 .

[88] Smith, D.C., Norman, R.D. and Swartz, M.L. Dental cements: Current status and future prospects In: Restorative Dental Materials An Overview Vol. 1 Reese, J.A. and Valega, T.M. eds, Quintessence Publ. Co., pp. 33-74, 1985.

[89] Smith, D.C. Dental cements In: Advances in Dental Research 2(1) International State-of-the-Art Conference on Restorative Dental Materials (1986, NIDR) Pp. 134-141, 1988. 
[90] Swartz, M.L. Dental cements: Reactor response, ibid pp. 142-146, 1988 .

[91] Smith, D.C. In-vitro performance of glass ionomer cements. Trans Acad. Dent. Materials 2(2), pp. 106-125, 1989.

[92] Antonucci, J.M., McKinney, J.E. and Stansbury, J.W. Formulation and evaluation of resin-modified glass ionomer cements trans. 13th Ann. Meeting Soc. Biomater. p. 225, 1987.

[93] Antonucci, J.M. and Stansbury, J.W. Polymer-modified glass ionomer cements. J. Dent. Res. 68:251 Abst. 555, 1989.

[94] Rusz, J., Antonucci, J.M., Eichmiller, F. and Anderson, M. Adhesive properties of polymer-and resin-modified glass ionomer cements. J. Dent. Res. 69:366 Abst. 2058, 1990.

[95] Sugawara, A., Antonucci, J.M., Takagi, S., Chow, L.C. and Ohashi, M. Formation of hydroxyapatite in hydrogels from tetracalcium phosphate/dicalcium phosphate mixtures. J. Nihon Univ. 31:372-381, 1989.

[96] Miyazaki, K., Takagi, S., Chow, L.C. and Antonucci, J.M. Polymeric calcium phosphate cements. J. Dent. Res. 69:367 Abst. 2068, 1990. 
II. WEAR RESISTANCE AND DURABILITY ASSESSMENT OF DENTAL COMPOSITE RESTORATIVE MATERIALS

\section{Overview}

This part of the annual report includes descriptions and results of experimental procedures used by the NIST Dental and Medical Materials Group to evaluate the performance of dental composite restorative materials. The methods employ in vitro wear testing, microhardness, mechanical measurements and microdefect analyses. The objectives are to use appropriate techniques to define and delineate fundamental wear mechanisms applicable to the in vitro and in vivo wear of these materials. The results from these studies facilitate the development of improved prototype composite restoratives here and at other laboratories, and, in some cases, to assess the extent of wear on the opposing enamel when the restorations are placed in stress-bearing occlusion (Class I and II).

This task is comprised of the following sections:

A. Wear and Durability Assessments of Composite Restoratives

Phase I. Recent Commercial Composites Which Appear Promising for Posterior Occlusal Application.

Phase II. Experimental Composites with Flexible Polymers.

(not active this period).

Phase III. Glass-Ionomer Cements: Conventional, Metal Filled, and Modified Experimental. (not active this period).

Phase IV. Susceptibility of Commercial Dental Composites to Topical Fluoride Gels. (not active this period).

Phase V. Experimental Studies on Experimental Composites Employing Apatite Reinforcing Fillers. (not active this period).

B. Assessment of Wear of Human Enamel Against Dental Restorative Counterfaces.

Phase I. Assessment of Wear of Human Enamel Against a Conventional Porcelain and a New Castable-Ceramic Counterface.

Phase II. Wear of Hydroxyapatite Against Dental-Alloy Counterfaces. (not active this active).

C. Wear Instrumentation (New Task).

Phase I. Methodology for Improved Wear Apparatus. 
Phase II. Selection, Acquisition, and Assembly of Electronic Components.

Phase III. Completion of Apparatus, Including Design and Assembly of Mainframe, (Drive Units, and Transducer Components.)

A. Wear and Durability Assessments of Composite Restoratives

\section{Background}

From microdefect analyses on in vivo worn restoration biopsies, environmental-generated damage was observed on both occlusal and nonstress-bearing surfaces of composite restorations [1,2] . Accordingly, the intraoral chemistry is believed to play a role in the in vivo degradation of these materials. For this reason an appropriate wear test should include the influence of a simulated intraoral environment. Accordingly, the wear test specimens are preconditioned in appropriate liquids prior to wear testing. Since dental composites comprise three essential, interrelated components, the polymer matrix, which is the continuous phase, a dispersed phase made up of inorganic and/or semi-inorganic reinforcing fillers, and a bifunctional interfacial phase, usually derived from silane agents, preconditioning media (e.g. aqueous ethanol, acids, etc.) were chosen which have potential for damaging these components.

Our previous work involved microhardness and wear tests, along with certain other tests, on commercial and experimental composite specimens in order to delineate their degradation mechanisms. In order to study potential problems with the matrix, the composite specimens were preconditioned (usually for one week) in selected solvent systems which simulate the food ingredients likely to be encountered in the oral cavity. When the solubility parameter of the solvent approximated that of the matrix resin, softening was observed by decreases in microhardness, which usually corresponded to enhanced wear $[3,4]$. The influence of preconditioning diminished during the course of wear as the wear-track depth into the specimen increased. This softening process is reversible with time. The bulk specimens can also exhibit gradient softening because of the nonattainment of equilibrium with the preconditioning media. In addition, both the critical interfacial phase and the filler phase of these composites may be subject to physical/chemical changes or damage which is induced, or augmented, by exposure to some solvents designed to simulate oral environments.

One serious limitation with dental polymers is that the curing process terminates at a low degree of conversion at the in situ temperature $\left(37^{\circ} \mathrm{C}\right)$. With the free-radical activated processes, the increase in viscosity during polymerization inhibits molecular diffusion which, in turn, prevents the proximation of reactive species, which, in the meantime, are used up by oxidation. We found that increasing the degree of cure decreased the extent of softening and improved the wear resistance of the specimens which would otherwise be damaged from 
preconditioning $[3,6]$. The degree of cure was enhanced by simply elevating the cure temperature.

Since a sufficient elevation in temperature would be impractical for in situ placed restorations, a more difficult and sophisticated approach involving changes in chemical structure is one of our current activities. It has to be remembered, however, that increasing the degree of cure may commensurately increase the polymerization shrinkage, which may lead to a greater loss of marginal integrity and corresponding leakage in application.

Accordingly, there are three important criteria to be satisfied for an appropriate matrix resin. These are (1) low solubility parameter (below the range of liquid food ingredients), (2) a high degree of cure (at in situ temperature) to further limit diffusion of liquids and subsequent swelling, and (3) low polymerization shrinkage to maintain marginal integrity. The first experimental composite used in this study was a hydrophobic, flexible resin comprising 70 wt \& poly(fluorourethane methacrylate) (PFUMA) and a siloxane diluent bis(methacryloxypropyl) tetramethyldisiloxane (BIS-MPTMS). These were mixed with a silanized fused-quartz filler. The polymerization shrinkage was reduced by using the prepolymer of PFUMA having about 10 repeat units which would correspond to a molecular weight of 12,060 $\mathrm{g} / \mathrm{mol}$.

A composite comprising a more flexible resin, polyfluoromethacrylate (PFMA), and other diluent monomers along with a photoinitiator for visible-light activation in addition to solely chemical (as with the PFUMA system) was formulated and evaluated. The results for the PFUMA and PFMA systems are summarized in previous annual reports [23,24] and references $[7,8]$.

The inorganic reinforcing filler was evaluated by preconditioning commercial dental composite specimens in weak intraoral acids which may damage the filler at the interface. Composites employing modified glasses with alkaline-earth elements to obtain radiopacity were more sensitive than the pure-silica-reinforced composites. It was determined that corrosion plays an important role in the degradation of composite restorations as evident from the leaching experiments of Söderholm $[9,10]$ and the wear and hardness measurements made at NIST [11]. The reason for including Phase $V$ (apatite fillers) was to determine if present radiopaque fillers could be replaced by apatite fillers combined with certain alkaline-earth elements to achieve radiopacity. It is expected that the apatite fillers will be less sensitive to corrosion from intraoral fluids [12].

Since glass-ionomer cements show good bonding properties to dental tissue [13], it was decided to include the evaluation of their wear behavior in our studies. The cure process of the glass-ionomer cements does not seem to be as viscosity limited as with the resin-based composites. Accordingly, higher degrees of cure can be reached at the in situ temperature with the former. 
With the three commercial glass-ionomer materials studied, the wear resistance of the water-preconditioned specimens was good except that the incidence of catastrophic failure from brittle fracture during wear was frequent [14]. Specimens preconditioned in dilute lactic acid revealed considerable chemical dissolution as apparent from electron micrographs and accelerated wear. More recent work [15] on a commercial silver-sintered glass-ionomer cement showed that, although the wear resistance improved considerably, the susceptibility to brittle fracture and chemical dissolution in lactic acid were still serious problems. These problems stressed the need for appropriate modification in the composition and structure of this class of materials for enhanced durability.

The so-called hybrid cement-composites (HCC) formulated at NIST were designed to overcome the deficiencies of glass-ionomer cements, namely, susceptibility to brittle fracture and dissolution in intraoral acids. The experimental system (HCC) contained a water-soluble monomer, 2hydroxyethyl methacrylate (HEMA), in the liquid (to be mixed with the powder) with appropriate catalysts added to a conventional glassionomer cement powder $[7 a, 7 b, 7 c, 24]$. After mixing, the two reactions (polymerization of HEMA and hardening of the glass-ionomer cement) occur simultaneously producing a "rubber toughened" glassionomer cement-composite, which is more flexible than the conventional glass-ionomer cements. The experimental results on the HCC specimens showed that the wear rate was slightly larger than that for the conventional glass-ionomer cement, but brittle fracture failures were absent. In addition, unlike the conventional glass-ionomer cements, the hardness was unchanged, and the wear was not enhanced from preconditioning in organic solvents and weak intraoral acids [7a].

Another specific source of damage to dental composites is from the application of topical fluoride agents which may eventually reach restorations even though not applied to them directly. In this connection, collaborative efforts were started with the University of Maryland Dental School at Baltimore to determine the effects of various topical fluorides on degradation and wear of composite resins. Very accurate weighing measurements and microdefect analyses revealed that, some damage resulted on the composites from gel treatments. Little or no significant changes resulted in the wear rates. The experimental results are summarized in references $[23,24]$ and [17].

\section{PROGRESS REPORT}

Phase I. Recent Commercial Composites Which Appear Promising for Posterior Occlusal Application.

Toward the end of this reporting period we agreed to participate in an ADA sponsored "round robin" wear study designed to evaluate several commercial posterior composites. This will help us to understand how our wear results compare with those from other laboratories now and for future reference. It will also provide us with an expanded data base 
which may be useful in the design and evaluation of future wear and degradation studies with new experimental composites.

An initial study was conducted on MACOR, the material proposed in the testing as a negative control (low wear specimen). MACOR is a machinable glass-ceramic (fluorine-rich mica phase in a glassy matrix) and is advertised as wear resistant material by the manufacturer. The initial results generated on the orginal pin-on-disk wear apparatus indicated that MACOR wore over 100 times as fast as most commercial composites (i.e. $50 \mu \mathrm{m} / 1000$ revs vs $.5 \mu \mathrm{m} / 1000$ revs). These results clearly indicate that MACOR exhibits severe wear under conditions with high stress concentrations as found in two-body wear apparatus such as the pin-on-disk type machines. MACOR is a two phase material which undergoes micro fracturing at points of very high local stress as encountered stress singularities (as was also observed in microhardness tests). The high wear rate of MACOR is probably caused by the wear pin plucking out mica particles on each revolution. These particles act as an abrasive and also increase the wear on the stainless steel pin. Although the wear mechanism of this multi-phase material may be of interest to investigate, MACOR should probably not be used as a negative, low-wear control for contact type wear machines.

Phase II. Experimental Composites with Flexible Polymers (not active this period)

The results of the performance evaluation of the dual-cured, flexibleresin composite described earlier were presented before the IADR Conference in March 1988 [16]. We originally thought that the flexible resins would reach a higher degree of cure because of their flexibility; however, their affinity to oxygen, which competes with the cure process, seems to offset the advantage of flexibility. In future studies employing fluorinated resins, we believe that either we have to find a way to keep oxygen (air) out during processing or incorporate a scavenger to absorb oxygen before, and during, polymerization. No further work has been done in this area this reporting period, but additional studies are proposed in the future.

Phase III. Glass-ionomer Cements: Conventional, Metal-Filled, and Modified Experimental. (task completed)

No additional wear or environmental resistance studies on glass-ionomer cements have been undertaken during this reporting period. A manuscript describing the wear and environmental resistance studies is essentially completed and will be submitted to WERB. A patent application on the hybrid cement-composite has been submitted.

Phase IV. Susceptibility of Commercial Dental Composites to Topical Fluoride Gels. (Not active this period).

No work was conducted in this area during this reporting period. 
Phase V. Experimental Studies on Experimental Composites Employing Apatite Reinforcing Fillers. (not active this period)

This phase has not been initiated as yet. As stated earlier, radiopaque composite fillers employing alkaline earth-modified glasses are sensitive to corrosion from the intraoral environment during wear. The conjecture is that corresponding apatites, e.g. barium, will satisfy the radiopacity requirements and be essentially insensitive to corrosion, which is enhanced by stress (stress corrosion).

Some work has been initiated, however, on the preparation of apatite and phosphate fillers in collaboration with the American Dental Association at NIST. If these appear to be promising, some wear and environmental resistance studies on corresponding composites may be conducted during the next reporting period.

B. Assessment of Wear of Human Enamel Against Dental Restorative Counterfaces

\section{Background}

Of increasing concern is the extent of wear on human enamel caused by occlusion with opposing restorations [18]. In our in vitro wear studies on commercial composites we found that the conventional composites with large rough particles, although not intended for occlusal applications, produced the most wear on the wear pins. It was encouraging to note, however, that the posterior microfills produced the least amount of wear among the composites tested. The wear on enamel from opposing composite restorations has been determined to depend upon the hardness and roughness (filler particle size and shape) of the composite [18]. In this connection an acceptance standard has been proposed by Lambrechts et al. [19] with respect to surface roughness, which is an indication of increased concern of this problem with respect to composites and other restoratives. In some of our work we are in the course of evaluating enamel wear resulting from commercial dental alloys and ceramics.

\section{PROGRESS REPORT}

Phase I. Assessment of Wear of Human Enamel Against a Conventional Porcelain and a New Castable-Ceramic Counterface.

In collaboration with the Naval Dental School (NDS) wear measurements on human tooth enamel against rotating counterfaces of a conventional porcelain and a new castable ceramic have been made employing fresh distilled water as a medium. Contrary to what was expected, the castable ceramic (Dicor), glazed with shading porcelain according to the manufacturer's specifications, produced more wear on the conical enamel pins than the unglazed ceramic. There was no significant difference between the enamel wear resulting from the unglazed ceramic and the porcelain. Accordingly, the conclusion from this study is that the shading should not be used in areas that will articulate against opposing teeth. 
The results of this preliminary study were presented at the IADR Conference in March 1988 [20]. A manuscript has cleared WERB and has been submitted to the Journal of Prosthetic Dentistry.

During the previous reporting period it was realized that the data could be deficient or perhaps, nondefinitive, for two reasons: (a) Insufficient data were obtained to clearly differentiate between the results for the glazed and unglazed ceramics, and (b) It is not clear that distilled water is an acceptable substitute for human saliva in this particular case. Accordingly the Naval Dental School (NDS) and NIST have decided to conduct additional work at our laboratory in an attempt to further delineate these results. The new tests will include constant immersion in both distilled water and a synthetic saliva (Xero-Lube, Scherer Laboratories, Inc., Dallas, TX). Two NDS residents indicate that immersion fluid does not effect the results which supported the previous findings of higher enamel wear rate on the glazed ceramic. A paper has been prepared and is under review at NDS.

Phase II. Wear of Hydroxyapatite Against Dental-Alloy Counterfaces . (task completed)

No further work was conducted during this reporting period.

C. Wear Instrumentation (New Task)

\section{Background}

The in vitro wear measurements mentioned throughout this chapter were made using a pin on disc apparatus described in Reference [21]. The original version was designed and assembled at the University of Indiana [22]. A second version was constructed at the National Bureau of Standards and essentially completed in 1976. This version was automatic, being programmed on a tape, but did not involve a central processing unit (CPU). The mechanical portion of the apparatus (involving unique components manufactured at NBS) was reinterfaced, and a programmable instrumentation controller with a CPU was incorporated [21]. This modification resulted in a more convenient, flexible, and reliable system. A new interfact to a Personal Computer was installed during this reporting period as described below in Phase I. A new computer program using GPIB interface software was completed which controls the original wear machine. This has resulted in more consistant performance (fewer computer errors). Over the past several years considerable activity was devoted to the design, acquisition, and construction and assembly of components to obtain a new and improved version of a pin and disc wear apparatus, which was completed near the end of this reporting period. The salient features are described below. 


\section{PROGRESS REPORT}

Phase I. Methodology for Improved Wear Apparatus

As a consequence of increased demand and new methodology in dental wear measurements, a new pin on disc wear apparatus was designed and assembled. The new version has independent stepping motors as drives for the three rotating specimen discs and other mechanical controls. These motors are fully programmable with respect to angle, rate, and function, e.g., constant speed, sine function, ramps, or steps. They also eliminate the need for the positioning scanners used in the present version.

As with the precursor, track-depth measurements using linear variable differential transformers (LVDT) may be taken at ten fixed positions around the track circumference to obtain a reliable average; however, by virtue of the stepping motors, this number also will be programmable.

The computer, which controls the apparatus, has the capability to do calculations for data processing including statistics, and thus will not require manual transfer of the vast amount of data acquired during each wear run to a different device. The computer program which controls the wear test has been completed.

During this reporting period the original wear machine was interfaced to a PC through a GPIB link. The original CPU was outdated and only supported cassette tape memory storage. The use of a PC allows ease of data access and analysis.

Phase II. Selection, Acquisition, and Assembly of the Electronic Components. (task completed)

Most of the commercially available electronic components for the new wear apparatus have been acquired and tested during previous reporting periods. These items include the computer (programmable in BASIC), hard and soft disc drives, a printer, and a data acquisition control unit, which comprises an integrating voltmeter, a 20-channel relay multiplexer with thermocouple compensation, a 16-channel general purpose switch, an 8-channel power controller, a 3-channel counter, and a stepping motor controller. The counter, one for each of the rotors, which may be running at different speeds, measures the number of disc revolutions by counting pulses from the LED's (light emitting diodes). These measurements ascertain the total wear-track length for each disc.

The stepping motors, their DC power supply and control circuits, and LVDT's and conditioning circuits, pulse-interrupt circuit, and GPIB (general purpose interface bus) interfaces have been acquired, or designed and constructed during the last reporting period. 
Phase III. Completion of the Apparatus, Including Design and Assembly of the Mainframe, Drive Units, and Transducer Components.

The mainframe, which is the mechanical portion of the apparatus including the drive motors and rotating disc assembly, the pin assembly, wear measurements assembly, and cam lifting assembles for the pin and measurement devices is now complete. All interconnections have been made, and computer programming has been done. A distinct advantage over the previous system is that the forthcoming one will allow wear testing under arbitrarily selected media.

During this reporting period, however, it was discovered that the stepper motors exhibited excessive resonance chatter at the speeds we wanted (27 RPM). Speed reduction gears and flexible belts have been purchased so that the motors can operate at higher speeds to avoid this resonance. 


\section{References}

[1] Wu, W. and Cobb, E. A silver staining technique for investigating wear of restorative dental composites, J. Biomed. Mat. Res. 5:343-348, 1981.

[2] Wu, W., Toth, E.E., Moffa, J.F. and Ellison, J.A. Subsurface damage of in vivo worn dental composite restorations, J. Dent. Res. 53:675-680, 1984 .

[3] Wu, W. and McKinney, J.E. Influence of chemicals on wear of dental composites. J. Dent. Res. 61 1180-1183 (1982).

[4] McKinney, J.E. and Wu, W. Chemical softening and wear of dental composites. J. Dent. Res. 64 1326-1331 (1985)

[5] McKinney, J.E. and Wu, W. Effect of degree of cure on hardness and wear on three commercial dental composites. AADR Abstr. 62 285, Abstr. 1047 (1983).

[6] Wu, W. Degree of cure and wear resistance of dental composites. IADR Abstr. $\underline{62}$ 671, Abstr. 192 (1983).

[7a] McKinney, J.E. and Antonucci, J.M. Wear and microhardness of two types of dental composites. IADR Abstr. $\underline{65}$ 848, Abstr. 1101 (1986).

[7b] Antonucci, J.M., McKinney, J.E. and Stansbury, J.W. Formulation and evaluation of resin-modified glass ionomer cements. Transactions of the 13 th Annual Meeting of the Society of Biomaterials, NY, NY, p. 255, 1987.

[7c] Antonucci, J.M. Toughened glass-ionomer cements. Trends and Techniques 5(3) p. 4, 1988.

[8] McKinney, J.E., Antonucci, J.M., and Venz, S. In vitro performance of an experimental composite containing a flexible fluorinated-polymer matrix. IADR Abstr. 66 128, Abstr. 175 (1987).

[9] Söderholm, K.J.M. Degradation of glass filler in experimental composites. J. Dent. Res. 60 1867-1875 (1981).

[10] Söderholm, K.J.M. Leaking of fillers in dental composites. $\underline{\text { ibid }} \underline{62}$ 126130 (1983).

[11] McKinney, J.E. Influence of acids of wear of composite restoratives. IADR Abstr. 63 199, Abstr. 256 (1984).

[12] Rawls, H.R., Legros, R.Z., and Zimmerman, B.F. A radiopaque composite restorative using an apatite filler. IADR Abstr. No. 64209 Abstr. 307 (1985).

[13] Hotz, P., Mclean, J.W., Sced, I., and Wilson, A.D. The bonding of glass ionomer cements to metal and tooth substrates. Br. Dent. J. 143 41-47 (1977). 
[14] McKinney, J.E., Antonucci, J.M., and Rupp, N.W. Wear and microhardness of glass-ionomer cements. J. Dent. Res. 66 1134-1139 (1987).

[15] McKinney, J.E., Antonucci, J.M., and Rupp, N.W. Wear and microhardness of a silver-sintered glass-ionomer cement. J. Dent. Res. 67, 831-835 (1988).

[16] McKinney, J.E., Antonucci, J.M., and Venz, S. In vitro performance of a dual-cured experimental composite containing a hydrophobic, flexible polymer matrix. IADR Abstr. 67, 261, Abstr 1188 (1988).

[17] Kula, K.S., McKinney, J.E., Kula, T.J., and Thompson, V.P. Effects of topical fluorides on weight and wear of a dental composite. IADR Abstr. 67, 381, Abstr. 2145 (1988).

[18] Lambrechts, P., Braem, M., and VanHerle, G. Evaluation of clinical performance for posterior composite resins and dental adhesives. Operat. Dent. 12, 53-78 (1987).

[19] Lambrechts, P. Braem, M., and VanHerle, G. Roughness of enamel as additional acceptance standard for posterior composites. IADR Abstr. 67, 262, Abstr. 1192 (1988).

[20] Palmer, D.S., Barco, G.B., Pelleu, G.B., Jr., and McKinney, J.E. Wear of human enamel against Dicor. IADR Abstr. 67, 381, Abstr. 2144.

[21] McKinney, J.E. Apparatus for measuring wear of dental composites. Wear 76 $337-347$ (1982).

[22] Powell, J.M., Phillips, R.W., and Norman, R.D. in vitro wear response of composite resin, amalgam, and enamel. J. Dent. Res. 54 1183-1185 (1975).

[23] Tesk, J.A., Antonucci, J.M., Brauer, G.M., de Rijk, W.G., McKinney, J.E., Stansbury, J.W., Venz, S., Lee, C.H., Sugawara, A., and Asaoka, K. Properties and interactions of oral structures and restorative materials. NISTIR 89-4048, issued May, 1989.

[24] Tesk, J.A., Antonucci, J.M., Brauer, G.M., McKinney, J.E., Stansbury, J.W., de Rijk, W.E., Venz, S., Keeny, S., Chiang, M.Y.M., Cheng, G.W., Miyazaki, K., Sato, Y., Asaoka, K. Properties and Interactions of oral structures and restorative materials. NISTIR 90-4291 


\section{Overview}

Porcelain fused-to-metal restorations constitute a major type of dental prosthesis. Wide fluctuations in the costs of dental restorative precious metal alloys have ensued over the past ten years. At the same time new materials for fabrication of non-metallic restorations have been introduced as have alloys of various kinds for cast metal restorations. The new materials can vary considerably in their fabrication characteristics and clinical performance. More reliable methods than now exist are needed to evaluate properties and develop methods to aid in prediction of clinical performance. For porcelainfused-to metal alloys the prime factors include thermal-stress compatibility, porcelain-metal system strength, alloy castability and the attendant capability of producing good fitting castings. Metrology plays an important role as the significance and relevance of materials properties needs to be more fully addressed in terms of relationships to clinical performance, reliability and predictability. Any measurement technique or process that can affect material properties or interpretation of clinical diagnoses rightfully belongs in this category.

In summary, this report focuses on dental alloy and ceramic systems, the use of Weibull statistics and finite element stress analysis for the determination of the strengths and origins of failure in bonded (and other) dental restorative systems, a critical analysis of the application of the diametral compression test and its relationship to other methods for obtaining tensile strengths, the application of a NIST developed algorithm for Weibull analyses of censored clinical data for the prediction of outcome of clinical studies, and investigation into the prospects for commercialization of gas plasma sterilization.

A. Porcelain-Alloy Compatibility (Thermo-mechanical stress)

PROGRESS REPORT

\section{Overview}

Residual and transient stresses in porcelain metal systems are considered to be major factors which influence their fabrication and service reliability. Compressive surface stresses may make restorations less prone to failure; tensile surface stresses and large interfacial stresses (body-opaque, opaque-metal) are considered less desirable. The geometries of porcelain-metal restorations are complex and influence the stresses developed from either fabrication and/or mastication etc.

New material systems, fabrication techniques, and restorative designs continue to be introduced. As the need for new materials and designs proceeds, it is desirable to have clearer understandings of how transient and residual stresses are developed, and how major material 
and fabrication factors can affect their magnitudes. Thus, the design of systems and fabrication methods can be more effectively guided by engineering principles and, when failures occur, they can be more readily interpreted. This study was undertaken to delineate effects of material properties, geometry (thickness) and fabrication (coolingheating) variables on the development of thermo-mechanical stresses.

\section{Accomplishments}

The viscoelastic and elastic properties of several dental porcelains and alloys have been used in viscoelastic models of porcelain slabs and porcelain-metal slabs to calculate the development of both transient stresses and residual stresses [1,2]. The factors included in the calculations were: Temperature dependent shear viscosities of porcelains $[3,4]$, temperature dependent coefficients of thermal expansion of alloys and porcelains $[2,5,6]$, temperature dependent elastic moduli [7], cooling rate dependence of glass transition temperatures (porcelain) [8], cooling rate dependent temperature distributions, several cooling rates, and several thicknesses.

The modeling has resulted in empirical equations which can describe interfacial and surface stresses as functions of cooling rates and specimen thicknesses. It was found that because of the high thermal gradients imposed during rapid cooling and viscoelastic behavior of porcelain that stress calculations based on elastic behavior give less precise results. Elastic calculations indicate stresses which vary inversely with the curvature; however, the viscoelastic calculations show stresses which vary inversely with the second (2nd) to seventh (7th) power of the curvature...i.e. $\sigma=\mathrm{K}(\rho \mathrm{D})^{-\mathrm{m}}$, where $\sigma$ is stress, $\mathrm{K}$ and $D$ are constants, $\rho$ is the curvature, and $m=2$ for interfacial stress, $m=7$ for surface stress. This non-linear behavior is in agreement with the predictions of Sherer [9]; however, Sherer's calculations ignore the effects of stresses introduced by the temperature gradient, so his calculations are only applicable for thin specimens and/or slow cooling where stresses due to the temperature gradients are small. Compressive surface stresses were found to develop more rapidly than interfacial stresses for the models developed. Also, the coefficient of thermal expansion of porcelain, above the glass transition temperature, was shown to have profound effects on development of beneficial surface compressive stresses...the higher the coefficient of thermal expansion, the greater the benefit.

Phase I Complete Development of the Required Model (FEM) for Calculation Stress in Porcelain and Porcelain-Metal Slabs

This Phase is completed (see NBSIR 88-3782) 
Phase II Calculate Effects of Variables, Included in Phase I, on Stress Distributions.

This Phase is completed for porcelain (see NBSIR 88-3782). A manuscript entitled "Transient and Residual Stresses in Dental Porcelains as Affected by Cooling Rates" has been published.

Phase II continues for calculation of stress in porcelain metal systems. A manuscript entitled "Transient and Residual Stress in a Porcelain-Metal Strip" has been published.

We have now investigated relationships between porcelain softening temperatures and the development of thermo-mechanical stresses in porcelain-metal slabs. A Voight model, as used previously for the simulation of stresses in porcelain slabs during cooling, was employed once more for calculations of deformation temperature as a function of applied stress and cooling rate; a Maxwell model was used for heating. In addition, an analytic approach was used for the calculation of porcelain softening temperatures. The calculations agreed very well with each other (Table \#1). Measured values of the porcelain load-bearing temperature also agreed with experimentally measured values (Table \#2). 
Table 1 Simulated and calculated deformation temperature. $T_{d} c$.

\begin{tabular}{rr|r|r}
\hline $\begin{array}{l}\text { Applied stress } \\
\text { stress }\end{array}$ & Calculated results & Simulated results \\
\hline 2 & 627 & \\
10 & 595 & 628 \\
50 & 566 & 595 \\
100 & 554 & 568 \\
\end{tabular}

Table 2 Measured and calculated load bearing temperature, $T_{b}{ }^{c}$.

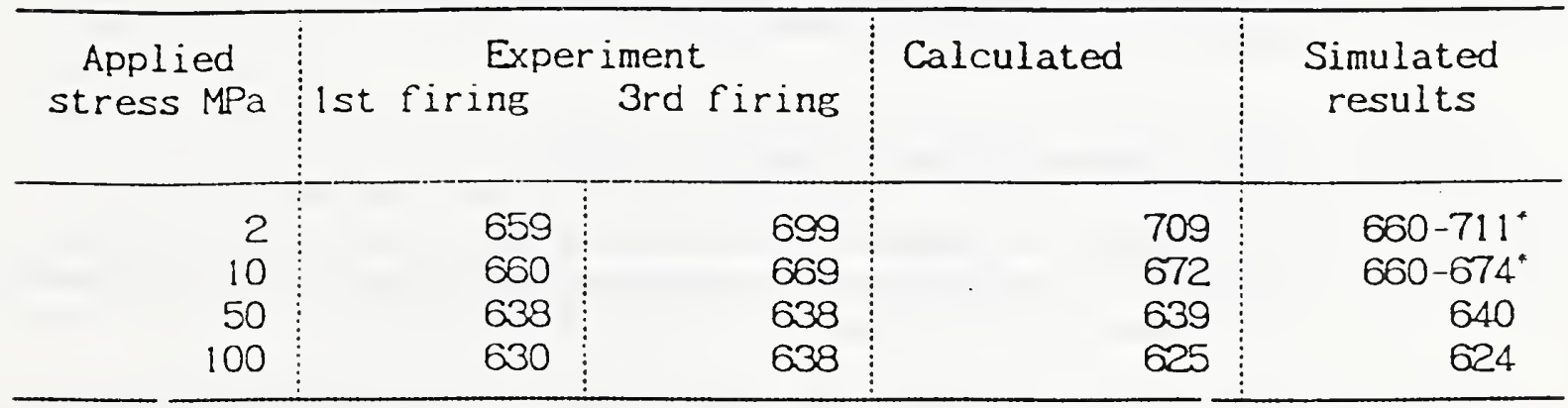

* Lower and upper values are simulated results calculated with assumptions which are explained in the manuscript accepted for publication. 
The following relationship was found:

$$
\sigma_{0} / \sigma=\alpha / \Delta \alpha
$$

where: $\sigma_{0}$ is the stress applied to a porcelain slab at the deformation temperature, $\mathrm{T}_{\mathrm{d}} ; \sigma$ is the elastic thermo-mechanical stress developed due to the difference in thermal expansion coefficients, $\Delta \alpha=\alpha_{p}-\alpha_{m}$, between porcelain and metal at $T_{d}$ and; $\alpha$ is the thermal coefficient of expansion of the porcelain. For commercial porcelains and alloys, $\alpha$ and $\Delta_{\alpha}$ are $\approx 30-40 \times 10^{-6}$ and $12-24 \times 10^{-6} /{ }^{\circ} \mathrm{C}$ respectively, leading to:

$\sigma_{0} / \sigma \simeq 1.2-3.3$

If $\mathrm{T}_{1}$ is a temperature at which a stress of $1 \mathrm{MPa}$ develops in porcelain due to cooling of porcelain-metal strips, $T_{d}$ for the porcelain (as determined with a dilatometer) should be evaluated with a load of 1.2-3.3 $\mathrm{MPa}$ on the push rod of the dilatometer during heating.

A manuscript entitled "Viscoelastic Deformation of Dental Porcelain and Porcelain Metal Compatibility" has been accepted for publication in Dental Materials.

Phase III Proceed with Input of Metal Properties for the Model and Complete the Input of Materials Parameters.

This phase has been completed. Results appear under Phase IV.

Phase IV Devise a Simple Analytical Representation of Stress-Strain for Porcelain-Metal Systems, if Possible for a Split Ring.

This phase has reached its intended objectives but will be reviewed as other work (Phase II) continues. This phase was reported on in NISTIR 90-4291.

Phase V Compare the Results of Model vs the Theory Developed by Scherer for a Simpler Porcelain-Metal System.

This phase has reached its intended objectives but will be rereviewed as results from additional calculations are obtained. This phase was reported on in NISTIR 90-4291.

Phase VI Extend the Results of the Model and Those from Part B (Following) on Porcelain-Alloy Compatibility to Investigation of the Use of Risk-of-Rupture.

This is a new phase. The possibility exists that risk-ofrupture analysis may be more meaningful that compatibility. This phase is currently postponed to continue work already begun, especially under Phase II. 
B. Porcelain-Alloy Compatibility: Strength of Porcelain-Metal Systems

\section{Overview}

The development of a porcelain-fused-to-metal (PFM) beam for the evaluation of PFM system strength under tension in four-point bending has provided a quantitative means of assessing the effects of various manipulations on the overall PFM system strength.

The manipulations to be evaluated are: 1) the effect of reglazing on a dental porcelain, 2) the effect of adding alumina to a porcelain composition (which alters the residual stress in the PFM system), and 3) the effect of submersion of the specimen in water for one week on the overall PFM system strength.

\section{PROGRESS REPORT}

Specimen preparation has been completed for the first 2 items to be considered and the manipulations 1) and 2) evaluated. The results were reported in NISTIR $90-4291$.

Phase I, Phase II, Phase III and Phase IV. These phases were last reported on in NISTIR 90-4291. As reported therein, this work was suspended, in nearly a completed state (except for Phase III), to concentrate on other sections of Part III of the work plan.

\section{Castability (Filling of a Mold with Cast Dental Alloy)}

\section{PROGRESS REPORT}

\section{Overview}

Numerous methods have been proposed in the past for determining various aspects of the casting of dental alloys. These have been discussed in NBSIR 86-3320.

A primary effort at NIST has been the development of a method for evaluating the ability to cast an alloy to fill a mold under prescribed casting conditions. For this purpose a method employing a polyester-grid mesh pattern has been chosen. (see NBSIR 87-3539, 1987 for more details).

\section{Accomplishments}

This study has now virtually been completed. (see NBSIR 88-3782). A manuscript entitled "Mesh Monitor Casting of $\mathrm{Ni}-\mathrm{Cr}$ alloys; Element Effects" has been published in the Journal of Dental Materials. 
D. Castability (Accuracy of Fit of Dental Castings).

\section{Accomplishments}

An experiment on the thermal expansion of a phosphate bonded investment has been performed using a total of 10 specimens. The findings indicate a change in strain which reproducibly coincides with the onset of the phase change in the filler of the investment. The observed expansion, even though reproducible both on heating and cooling, is of such magnitude (208 net strain) that it most likely is an electrical phenomenon that is temperature dependent.

The strain gauges, as they are currently available for high temperature investigations, are not suitable for embedding in high temperature casting investments.

This project has been terminated, with two manuscripts having been published in J. Prosthet Dent.

\section{E. Solderability}

This project has been discontinued as explained in a previous report NBSIR-87-3539, 1987.

F. Metrology and Analysis: Measurements for Characterization of Dental Materials

All current work related to this section is reported in section $H$ which deals with relationships between metrology and clinical performance.

G. Metrology and Analysis: Occlusal Force Indicator

No actual development of the occlusal force indicator took place using the piezo-electric polymer polyvinylidene fluoride (PVDF).

During May 1988, W. de Rijk attended a seminar by the research staff of Tekscan Inc., the manufacturer of the T-Scan system for occlusal force measurement. The $\mathrm{T}-\mathrm{Scan}$ is a system which uses a thin (60 micrometers) wafer as a transducer and has a PC-AT type computer for data gathering and processing. The instrument has only very recently been introduced and is conceptually similar to the system suggested in our initial proposal. The transducer in this system is based on the change in electrical resistance in a carbon filled polymer. The signal processing unit as made by the company is more than adequate, but the clinical effectiveness of the transducer could be vastly improved with a bite wafer that is thinner and that has less rigidity. The current assessment is that the T-Scan system could be significantly improved if a PVDF transducer of less than 10 micrometers thickness and low rigidity could be made. 
Due to concentration of efforts on other areas described in this report no progress was attempted, especially in view of the introduction of such device for the profession and because of the considerably more complex effort needed for refinements as just described.

\section{H. Metrology and Clinical Performance}

Phase I. Development of Algorithms and Software for the Reduction of Data, Using the Weibull Distribution.

The software used for the processing of fracture data has been improved such that now the data, maximum likelihood estimates, and calculated cumulative probability curves can be exported to commercial graphics routines.

The Weibull distribution can be used to predict the characteristic lifetime of a given population even if only a few early failures have occurred. While this is not the only distribution which can accomplish this it is a very wieldy distribution and, if it applies, can be used to great advantage in an easily understood manner with a simple software routines. How to use the censored data with nonuniform insertion and removal times has been reported on in NISTIR 90-4291. Efforts are now in progress to review these applications critically and to obtain data which can be used to assess applicability.

Phase II Analyses of Resin-Metal-Bond Tests.

For bonded specimens subjected to uniform tensile stress, failures may be suspected an originating within the volume, $V$, of the material, along external surfaces of area, $S$; within the interfacial area, $I$; and along the interfacial surface junction of length, $\ell$. If uniaxial, uniform stress tensile tests are conducted on two or more sets of bonded specimens having significantly different values of $\mathrm{V}, \mathrm{S}, \mathrm{I}$ and $\ell$ equation 4 may be used to determine the origin of failures, i.e., only one set of relations using $\mathrm{V}_{1} / \mathrm{N}_{2}, \mathrm{~S}_{1} / \mathrm{S}_{2}, \mathrm{I}_{1} / \mathrm{I}_{2}$, or $\ell_{1} / \ell_{2}$ should uniquely satisfy the relation $\frac{\sigma_{0.1}}{\sigma_{0,2}}=\left(\frac{\delta_{2}}{\delta_{1}}\right)^{1 / \mathrm{m}}$

Complex nonuniform stress distributions can arise due to differences between properties of the bonding and bonded materials and also due to geometric discontinuities; in those cases $B$ must be evaluated in a form other than eqn $3 a$ (philosophical and real questions exist if the bond thickness, $t$, becomes vanishingly small). $010^{10}$ and Nakabayashi ${ }^{11}$ among others have recognized the potential effects of bond thickness, $t$, geometry and properties on measured bond strengths.

The finite element method may be used to determine $\sigma(\delta)$ and we have done this for two metal beams, Fig. 1, of elastic modulus, $\mathrm{E}_{\mathrm{m}}=180 \mathrm{GPa}^{7}$, joined by a bonding layer with $\mathrm{E}_{\mathrm{b}}=3.5 \mathrm{GPa}$. 
Under pure bending the stress throughout the near surface layer for various thickness is as shown in figs. 2, 3, 4.

In this case, the relationship between the values for $\sigma_{0}$ is approximated as

$\sigma_{0,1}=\sigma_{0,2}\left(\frac{\sum \delta_{i, 2}}{\sum_{j, 2}\left(\sigma_{i, 2}\right)^{\mathrm{m}}}\right)^{1 / \mathrm{m}}$

eqn 6

With this relationship corrections can only be made when the $m$ values are the same for each test and when all test dimensions are the same except for the bond thickness. Ritter has shown the utility of this approach. Also, only one set of $\delta_{i}^{\prime} s, \sigma_{i}^{\prime} s$, and $\delta_{j} ' s, \sigma_{j}^{\prime} s$ should be able to unambiguously satisfy the relationship shown in eqn 6 .

Hence, by uniquely varying V, S, I etc. and using the appropriate stress distribution it should be possible to construct relationships between strengths obtained from tests on specimens with different geometries, (thickness of bond layer, specimen dimensions etc.) and from related test modes (tension vs tension, shear vs shear etc.) and unify some of the test results. Further it should be possible to identify origins of failure associated with those strengths.

Accomplishments

For resin bonded metals with geometry as shown in fig. \#1 we have found the value of $m(11.5)$ is the same from bending fractures of specimens with 50 and $200 \mu \mathrm{m}$ thick bond layers and from uniaxial tensile fractures from $50 \mu \mathrm{m}$ thick specimens. For $200 \mu \mathrm{m}$ thick bond layer tensile specimens the $\mathrm{m}$ value is 7.4 and is shifted toward that of a neat specimen of bond material, $(\mathrm{m}=$ 6.8 ) which can have only surface or volume failures; this indicates that the bond failures for bending and for $50 \mu \mathrm{m}$ tensile bond specimens originate at the interface or the surface interfacial junction. When the stress distributions from finite element modeling (figs. 2,3,4) are added to the analyses, the ratios, $R$, of the characteristic strengths (from eqn 6) are as shown in Table \#3. These results identify the interface as the failure origin for the bending specimens. Recent results for the analysis of tensile failures show that the origin of $50 \mu \mathrm{m}$ thick bond tensile failures is also in the interface as implied from the values of $\mathrm{m}$. It should be noted that this shows that the corrected $\sigma_{\circ}^{\prime} ' s$ are identical when the interfacial areas are taken into account, whereas the "bond strengths" calculated from simple uniform stress or bending stress assumptions, with no thickness variations taken into account, range from 70 to 110 $\mathrm{MPa}$. 
Table 3 .

Ratios $R=\sigma_{0,1} / \sigma_{0}, 2$, for assumed failure origins, compared with the experimentally determined $R$.

$\begin{array}{ll}\text { ASSUMED FAILURE ORIGIN } & \text { RATIO } \\ \text { Volume } & 1.12 \\ \text { Surface } & 1.25 \\ \text { Interface } & 0.993 \\ \text { Surface } & 1.23\end{array}$

The 958 confident experimental range of $\mathrm{R}$ is 0.955 - 1.11; this identifies the interface as the most likely origin for failures

One note...extreme care in alignment is also demonstrated to be important...deliberately mis-aligning tensile specimens by $1^{\circ}$ results in apparent drops in bond strengths - 508, to within the range reported in the literature, $10-50 \mathrm{MPa}$. While this is probably not the only reason for drop in apparent bond strength, it clearly is one...others can involve geometric discontinuities in the test set-up...these were avoided in the present tests.

We are now in the process of checking to see if the same results are obtained if the finite element mesh is refined.

Phase III Analysis of Tensile Data from Composites Exposed to Food Simulating Fluids.

This work was reported on in NISTIR 90-4291.

Efforts on this work have been delayed until FY91 or beyond in order to focus more on the dimetral-tensile test method per-se and its applicability to dental materials testing.

I. Metrology and Analysis: Stress in Dental Composites Bonded to Teeth

This activity is concerned with guiding:

a) the development of new cavity preparations

b) restorative placement techniques

c) new materials development

d) clinical studies

Due to a concentration of efforts on some of the other topics covered in Section III this work has not progressed beyond what was reported in NISTIR 90-4291. 
J. Metrology: Sterilization of Dental Instruments: The Effect of Gas Plasma Sterilization

\section{Overview}

The patent and other literature address the ability to sterilize materials, equipment and devices by the use of gaseous glow discharges (plasmas) $[12,13,14,15,16,17,18]$. Studies in this laboratory have indicated that sterilization can be achieved in very short time periods with the use of microwave generated plasmas. Sterilization times of the order of $30 \mathrm{sec}$ to a few minutes were achieved. Because other sterilization methods can be environmentally damaging (ethylene oxide with freon wash) ${ }^{19}$ or degrading to materials (dry heat, steam autoclave) it is desirable to have alternative methods of sterilization. Major questions remain to be answered regarding the use of glow discharges; among these are the effects on different materials such as metals, plastics and ceramics. Clearly, the addition of any rapid-acting device to the armamentarium for sterilization holds promises of immense benefits for applications in dental and medical offices, clinics and hospitals.

Before the effects of Microwave Generated Gas Plasma (MGGP) sterilization on different materials could be effectively studied it was necessary to understand in a more quantitative manner the range of operating conditions under which sterilization might be achieved. This is because MGGP probably involves a number of mechanisms, each independently capable of achieving sterilization but with different effects on materials, different kill rates and different abilities for effectiveness in hardto-get-at places (such as grooves). This involved the development of suitable biological indicators (BI's) of sterilization as well as the varying of a range of operating conditions. Possible kill parameters involve ultraviolet radiation, heat, reactive chemical species and charged particle bombardment ${ }^{20}$.

\section{PROGRESS REPORT}

\section{Accomplishments}

Phase I, Development of Plasmas

Phase II, Effects of Plasmas on Spores

Phase III, Effect of Plasma on Materials

Phase IV, Development of Suitable Biological Indicators for

Controlled Sterilization Studies

Phase V, Characterization of Plasmas

Various aspects of each phase have been pursued as the study progressed. The results are summarized in the following.

Dental burs which were contaminated by suspensions of $10^{9}$ colony forming units (CFU's) of B-subtilis spores were sterilized by gas plasmas in 30-120 seconds. However the actual contamination level on the burs was unknown. We now believe that the number of CFU's was $10^{3}-10^{4}$. 
As of this writing, we have developed the needed BI's; established the most likely mechanisms of sterilization under different conditions; established half, full and three phase power kill-relationships; and developed temperature and voltage probes. We have also developed some power-energy-time-temperature relationships pertinent to sterilization, and explored the effects of substrate materials on killing as well as geometric parameters involved in killing, e.g. in controlled hard-to-getat places. Based on these accomplishments a pilot study has also been initiated on the effects of some sterilization conditions on the cutting efficiency of dental burs.

Characterization of plasma constituents has been difficult and not successful. The methods attempted included vacuum uv emission spectroscopy and absorption spectroscopy.

Results of the kill-kinetics studies are reproducible with controls of pressure, time, power and gas species.

55 
References

[1] Asaoka, K. and Tesk, J.A.: Transient and residual stresses in dental porcelain as affected by cooling rates, Dent. Mater. J. 8: 9-25, 1989.

[2] Asaoka, K. and Tesk, J.A.: Transient and residual stress in a porcelainmetal strip, J. Dent. Res. 69: 463-469, 1990.

[3] Tesk, J.A., Hinman, R.W., Whitlock, R.P., Holmes, A. and Parry, E.E.: Temperature dependence of shear viscosity for several dental porcelains, J. Dent. Res. 59: Abstract \#839, March, 1981.

[4] Bertolotti, R.L. and Shelby, J.E.: Viscosity of dental porcelain as a function of temperature, J. Dent. Res. 58: 2001-2004, 1979.

[5] Farshirst, C.W., Anisavia, K. J., Hashings, D.T., Ringle, R.D. and Twiggs, S.W.: Thermal expansion of dental alloys and porcelain, J. Biomed. Mats. Res. 14: 435-446, 1980.

[6] Whitlock, R.P., Tesk, J.A., Widera, G.E.O., Holmes, A. and Parry, E.E.: Consideration of some factors influencing compatibility of dental porcelain and alloys, Proc. Int. Precious Metals Conf. 4: 273-282, 1981.

[7] Käse, H.R., Tesk, J.A., and Case, E.D.: Elastic constants of two dental porcelains, J. Mater. Sci. 20: 524-531, 1985.

[8] Moynihan, C.T., Easteal, A.J., Wilder, J. and Tucker, J.: Dependence of glass transition temperature on heating and cooling rate, J. Phys. Chem. 78: 2673-2677, 1974 .

[9] Scherer, G.W.: Viscoelastic analysis of the split ring seal, J. Am. Ceram. Soc. 66, 135-139, 1983.

[10] Oilo, G. and Evje, D.M., A bend test for measuring cement-dentin bond, Dent. Mater. 4: 98-102, 1988.

[11] Nakabayashi, N., Tomata, K. and Matsumura, H.: Relationship between the shape of adherend and the bond strength, J. Jap. Soc. Dent. Mater. and Dev. 6: 422-425, 1987.

[12] Menashi, W.P. Treatment of surfaces, U.S. Patent 3,383,163, May 14, 1968.

[13] Fraser, S.J. et al Sterilization and packaging process utilizing gas plasma, U.S. Patent 3,851,436, Dec. 3, 1974.

[14] Boucher, R.M.G. Seeded gas plasma sterilization method U.S. Patent 4,207,286, June 10, 1980.

[15] Bithell, R.M. Plasma pressure pulse sterilization, U.S. Patent 4,348,357, Sep. 7, 1982 . 
[16] Jacob, A. Process and apparatus for dry sterilization of medical devices and materials, U.S. Patent 4,801,427, Jan. 31, 1989.

[17] Ribner, A. Microwave plasma etching machine and method of etching, U.S. Patent 4,804,431, Feb. 14, 1989.

[18] Boucher, R.M.G State of the art in gas plasma sterilization, Med. Dev. Diag. Ind., Feb 1985, pp 51-56.

[19] Ellis, J.R. EtO: does it have a future?, Med. Dev. Diag. Ind., Feb. 1990, PP 50-51.

[20] Disinfection, sterilization, and preservation, ed. Block, S.S.; Lea \& Febiger, Philadelphia, (1983). 


\section{Publications}

Antonucci, J.M., Stansbury, J.W. and Venz, S. Synthesis and properties of a polyfluorinated prepolymer multifunctional urethane methacrylate in: Progress in Biomedical Polymers; Editors, C.G. Gebelein and R.L. Dunn, Plenum Publishing Co., New York, 1990.

Antonucci, J.M., Stansbury, J.W., Fowler, B.O. and Eichmiller, F. Synthesis, characterization and evaluation of vinyl metallocarboxylates. Poly Preprints $31,64,1990$.

Brauer, G.M. and Lee, S. Metharcylate oligomers with pendant isocyanate groups as tissue adhesives in: Progress in Biomedical Polymers; Editors, C.G. Gebelein, and R.L. Dunn, Plenum Publishing Co., New York , 1990.

Stansbury, J.W. Cyclopolymerizable monomers for use in dental resin composites. J. Dent. Res. $\underline{69}$ 844-848 (1990).

Stansbury, J.W. and Bailey, W.J. Evaluation of spiro orthocarbonate monomers capable of polymerization with expansion as ingredients in dental composite materials in: Progress in Biomedical Polymers; Editors, C.G. Gebelein and R.L. Dunn, Plenum Publishing Co., New York 133-139-1990.

Tesk, J.A., Antonucci, J.M., Brauer, G.M., McKinney, J.E., Stansbury, J.W., de Rijk, W.G., Venz, S., Keeny, S., Chiang, M.Y.M., Cheng, G.W., Miyazaki, K., Sato, Y., and Asaoka, K., Properties and interactions of oral structures and restorative materials. NISTIR 90-4291, May 1990.

Asaoka, K. and Tesk, J. A. Transient and residual stress in a porcelain-metal strip. J. Dent. Res., 69, \#2, 463-469, Feb., 1990.

Engler, R.A., de Rijk, W.G., Tesk, J.A. and Morris, D. Multi-dimensional internal settiang expansion of a phosphate-bonded casting investment measured with strain gauges. J. Prosthetic Dent., 3:353-358, March, 1990.

de Rijk, W.G., Brown, W.E. and Chow, L.C. The clinical evaluation of a hydroxyapatite forming paste in the treatment of dental hypersensitivity. Biomedical Engineering. Current Concepts VI, S. Saha. ed. Pergamon Press (in press).

de Rijk, W.G., Tesk, J.A., Penn, R.W. and Marsh, J. Applications of the Weibull method to statistical analysis of strength parameters of dental materials. Progress in Biomedical Polymers, Editors, Dunn, R. and Geberlein, G. Plenum Press, New York, 1990 pp. 141-147. 
Manuscripts Under Review or Accepted for Publication

Stansbury, J.W. Difunctional and multifunctional monomers capable of cyclopolymerization. Submitted to Macromolecules.

Antonucci, J.M., Fowler, B.O. and Venz, S. Filler system based on calcium metaphosphates. Accepted for publication in Dental Materials.

Asaoka, K. and Tesk, J. A. Viscoelastic deformation of dental porcelain and porcelain-metal compatibility. Accepted by Dental Mater.

Chiang, M.Y.M. and Tesk, J.A. Applicability of diametral-compression testing of dental materials. Submitted to J. Dent. Res.

Dental Biomaterials and Engineering Frontiers for the 90's. Accepted for publication in "Proceedings of 3rd International Kyoto Symposium on Biomedical Engineering", Nov. 20, 1990.

\section{Conferences/Special Meetings}

Antonucci, J.M. Chairman, Gordon Research Conference on the Science of Adhesion, August, 1990.

\section{Contributed Talks}

Antonucci, J.M., Stansbury, J.W., Fowler, B.O. and Eichmiller, F. Monomer systems based on multivalent metal monocarboxylate monomers. IADR meeting, Cincinnati, OH., March, 1990.

Anderson, M., Keeny, S., Olson, G., Johnsonbaugh, D. Bridges, M. Crespo, J.R., Antonucci, J., Goodman, C. and Tesk, J.A. Sterilization by microwave generated gas plasmas. IADR meeting, March, 1990.

Cheng, G.W., Stansbury, J.W. and Antonucci, J.M. Synthesis of novel highly fluorinated multifunctional vinyl monomers and oligomers. IADR meeting, Cincinnati, OH, March, 1990.

de Rijk, W.G., Tesk, J.A., and Marsh, J. Weibull parameter changes for a composite resin during exposure to ethanol. IADR meeting, March, 1990.

Keeny, S., Sato, Y., and Tesk, J.A. Bond strength of resin-bonded systems in tension and bending. IADR meeting, March, 1990.

Matthews, T.J., Antonucci, J.M. and de Rijk, W.G. The effect of post cure storage time on diametral tensile strength of composites. IADR meeting, Cincinnati, OH, March, 1990.

Rusz, J., Antonucci, J.M., Eichmiller, F. and Anderson, M. Adhesive properties of polymer- and resin-modified glass ionomer cements. IADR meeting, Cincinnati, OH, March, 1990. 
Strassler, H.E., Antonucci, J.M. and Marsh, J. Organozirconates as coupling agents for glass filled dental composites. IADR meeting, Cincinnati, OH, March 1990.

Stansbury, J.W. Evaluation of a new multifunctional oligomer for dental composites. IADR meeting, Cincinnati, OH, March, 1990.

Stansbury, J.W. Synthesis and polymerization of difunctional and multifunctional monomers capable of cyclopolymerization. Meeting of the American Chemical Society, Boston, MA, April, 1990.

Tesk, J.A., Chiang, M.Y.M., Tank, J., and Keeny, S. Stress in an "adhesive" bond layer. IADR meeting, March, 1990.

\section{Invited Talks}

Antonucci, J.M., Stansbury, J.W. and Cheng, G.W. A facile synthesis of novel fluorinated multifunctional acrylates. Meeting of the American Chemical Society, Fluorine-Containing Polymers Symposium, Boston, MA, April, 1990.

Antonucci, J.M., Stansbury, J.W. Fowler, B.O. and Eichmiller, F. Synthesis, characterization and evaluation of vinyl methallocarboxylates. Meeting of the American Chemical Society, William J. Bailey Memorial Symposium, Washington, D.C., August, 1990.

Stansbury, J.W. Synthesis and polymerization of difunctional and multifunctional monomers capable of cyclopolymerization. Chemical Society of Washington, Members Poster Session, Washington, D.C., April, 1990.

Stansbury, J.W. Synthesis and ring-opening polymerization of spiro orthocarbonates. Meeting of the American Chemical Society, Willian J. Bailey Memorial Symposium, Washington, D.C., August, 1990. 


\section{TITLE AND SUBTITLE}

Properties and Interactions of Oral Structures and Restorative Materials

5. AUTHOR(S)

J.A. Tesk, J.M. Antonucci, M.Y.M. Chiang, W.E. de Rijk, S.M. Keeny, III, J.E. McKinney, J.W. Stansbury, K. Asaoka, G.W. Cheng, T. Matthews, K. Miyazaki, J. Tang,

6. PERFORMING ORGANIZATION (IF JOINT OR OTHER THAN NIST, SEE INSTRUCTIONS) U.S. DEPARTMENT OF COMMERCE NATIONAL INSTITUTE OF STANDARDS AND TECHNOLOGY GAITHERSBURG, MD 20899 7. CONTRACT/GRANT NUMBER

9. SPONSORING ORGANIZATION NAME AND COMPLETE ADDRESS (STREET, CITY, STATE, ZIP)

DOCUMENT DESCRIBES A COMPUTER PROGRAM; SF-185, FIPS SOFTWARE SUMMARY, IS ATTACHED.

11. ABSTRACT (A 200-WORD OR LESS FACTUAL SUMMARY OF MOST SIONIFICANT INFORMATION. IF DOCUMENT INCLUDES A SIONIFICANT BIBUOORAPHY OR UTERATURE SURVEY, MENTION IT HERE.)

The research program described herein is designed to achieve a number of objectives leading to improved dental restorative materials, techniques, and applications of dental materials science for improved dental health care in general. Some of the research in dental composites is directed toward developing generic polymer science potentially useful for composite applications, e.g., durable resin matrices and stronger more durable coupling between fillers and resins. Improved reinforcement is sought by defining the type, and percentages of fillers which will result in improved performance of composites. Methods for reducing polymerization shrinkage and attendant stress and marginal leakage are also explored. Cements are investigated and basic formulations developed for lower solubility, higher biocompatibility, higher strength, greater toughness and adhesion to various substrates including enamel and dentin. Analysis techniques include IR spectroscopy, chromatography, $x$-ray analysis, mechanical testing, and dilatometry. Another major effort is directed at elucidating the fundamentals involved in wear and degradation of dental composites and restoratives. Wear and hardness measurement techniques are used as well as identification of the origins and sources of flaws leading to failure. Weibull statistical analysis is expected to provide useful information for this task. In this regard an objective is to investigate improved correlations between clinical results of wear and failure with 12. I laboratory test data. Metrology and analysis constitutes the underlying theme of investigations into porcelain-metal systems, casting of dental alloys and the expansion of dental casting investments.

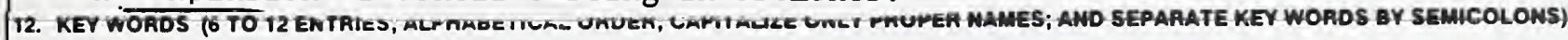

Dental engineering; dental restoratives; dental materials

\section{AVAILABILTYY}

UNUMITED

FOR OFFICIAL DISTRIBUTION. DO NOT RELEASE TO NATIONAL TECHNICAL INFORMATION SERVCE (NTIS).

ORDER FROM SUPERINTENDENT OF DOCUMENTS, U.S. GOVERNMENT PRINTING OFFICE, WASHINGTON, DC 20402.

ORDER FROM MATIONAL TECHNICAL INFORMATION SERVICE (NTIS), SPRINOFIELD, VA 22161. 


I

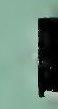

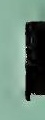

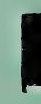

,

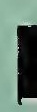

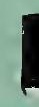

,

,

,

,

,

,

,

,

,

,

,

1 